\title{
Adsorption for efficient low carbon hydrogen production: part 2-Cyclic experiments and model predictions
}

\author{
Anne Streb ${ }^{1}$ (D) Marco Mazzotti ${ }^{1}$ (D)
}

Received: 14 October 2020 / Revised: 29 January 2021 / Accepted: 16 February 2021 / Published online: 9 March 2021

(c) The Author(s) 2021

\begin{abstract}
Hydrogen as clean energy carrier is expected to play a key role in future low-carbon energy systems. In this paper, we demonstrate a new technology for coupling fossil-fuel based hydrogen production with carbon capture and storage (CCS): the integration of $\mathrm{CO}_{2}$ capture and $\mathrm{H}_{2}$ purification in a single vacuum pressure swing adsorption (VPSA) cycle. An eight step VPSA cycle is tested in a two-column lab-pilot for a ternary $\mathrm{CO}_{2}-\mathrm{H}_{2}-\mathrm{CH}_{4}$ stream representative of shifted steam methane reformer (SMR) syngas, while using commercial zeolite $13 \mathrm{X}$ as adsorbent. The cycle can co-purify $\mathrm{CO}_{2}$ and $\mathrm{H}_{2}$, thus reaching $\mathrm{H}_{2}$ purities up to $99.96 \%, \mathrm{CO}_{2}$ purities up to $98.9 \%, \mathrm{CO}_{2}$ recoveries up to $94.3 \%$ and $\mathrm{H}_{2}$ recoveries up to $81 \%$. The key decision variables for adjusting the separation performance to reach the required targets are the heavy purge (HP) duration, the feed duration, the evacuation pressure and the flow rate of the light purge (LP). In contrast to that, the separation performance is rather insensitive towards small changes in feed composition and in HP inlet composition. Comparing the experimental results with simulation results shows that the model for describing multi-component adsorption is critical in determining the predictive capabilities of the column model. Here, the real adsorbed solution theory (RAST) is necessary
\end{abstract}

This is the second part of a two-part contribution to the Special Issue of Adsorption dedicated to the memory of Dr. Shivaji Sircar, and honoring his multi-faceted pioneering contributions to Adsorption Science and Technology. For the senior author of this work, Dr. Sircar has been, during the last three decades, a role model and a mentor, with his scientific insight and inspiring ideas, as well as with his kindness and friendship. Dr. Sircar's ideas have influenced everything from the foundations of adsorption to industrial practice, and his impact on the field of adsorption remains unsurpassed. He will be dearly missed.

Extended author information available on the last page of the article 
to describe all experiments well, whereas neither extended isotherms nor the ideal adsorbed solution theory (IAST) can reproduce all effects observed experimentally.

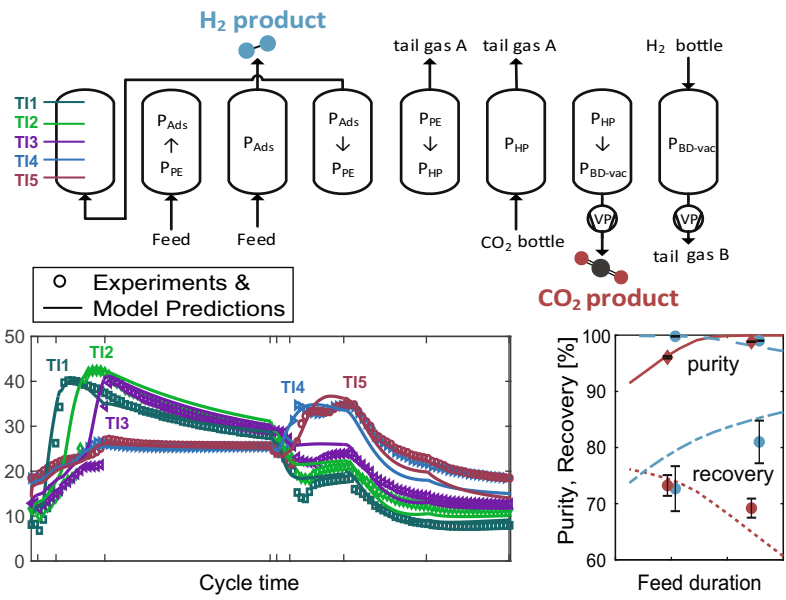

Keywords VPSA $\cdot \mathrm{CO}_{2}$ capture $\cdot$ Hydrogen purification $\cdot$ Cyclic experiments $\cdot$ Simulation and modeling $\cdot$ Adsorbed solution theory

\section{Introduction}

Counteracting climate change has become one of the big challenges of the twenty-first century. For the necessary transition towards a low carbon industry and energy sector, low carbon energy carriers are of utmost importance. Hydrogen can be such an energy carrier with potential uses spanning from industrial fuel or feedstock over transportation to domestic heating, and therefore has become one of the cornerstones in the energy transition of many countries $[1,2]$. For it to play a key role in future low carbon energy systems, however, it is vital that $\mathrm{H}_{2}$ is produced without associated $\mathrm{CO}_{2}$ emissions. Possible production pathways thus include electrolysis using renewable energy, production from biogenic sources, or production from fossil fuels with carbon capture and storage (CCS) throughout the production process. In contrast to that, electrolysis using carbon intensive electricity like the current grid-mix in most countries, or producing $\mathrm{H}_{2}$ from fossil fuels without CCS, will result in an $\mathrm{H}_{2}$ product with high associated greenhouse gas emissions.

Today, standalone production of $\mathrm{H}_{2}$ is mainly fossil fuel based and responsible for emissions of more than $800 \mathrm{Mt}$ $\mathrm{CO}_{2} / \mathrm{y}$ for the production of approximately $70 \mathrm{Mt} \mathrm{H}_{2} / \mathrm{y}$ [2]. Steam methane reforming (SMR) of natural gas is the most prominent technology accounting for $76 \%$ of the total production. Coupling fossil fuel based $\mathrm{H}_{2}$ production with CCS has several advantages compared to $\mathrm{H}_{2}$ production from electrolysis using renewable energy. One important factor is the cost: even after factoring in the decreasing cost of electrolysers and of renewable energy in the long run, the cost per $\mathrm{kg} \mathrm{H}_{2}$ is expected to remain at a level of around 2.5-3.5 USD in central, northern and eastern Europe, and as high as 4 USD in Japan [2]. This is significantly more expensive than the estimated cost of $\mathrm{H}_{2}$ produced from SMR coupled with CCS of just above $2 \mathrm{USD} / \mathrm{kg} \mathrm{CO}_{2}$ or just below 3 in Japan [2, 3]. Other advantages are the experience with already existing large scale $\mathrm{H}_{2}$ production facilities, thus also making scale up easier, and the possibility to replace fossil with biogenic fuel, and thereby, when coupled with CCS, deliver negative lifecycle emissions [4].

When coupling an SMR process with $\mathrm{CCS}$, the $\mathrm{CO}_{2}$ can be captured at different locations-from the reformer flue gas, after the water-gas shift reactor but before entering the pressure swing adsorption (PSA) unit for $\mathrm{H}_{2}$ purification, or from the PSA tail gas-and using different separation technologies such as cryogenic separation, membranes, absorption, and adsorption [5, 6]. Several pilot scale and large scale projects are currently capturing $\mathrm{CO}_{2}$ from $\mathrm{H}_{2}$ production facilities(Quest, Alberta, Canada, [7]; Air Products Steam methane reformer, Texas, US, [8]; Port Jérôme $\mathrm{CO}_{2}$ capture plant, France, [9]; Tomakomai CCS demonstration project, Japan, [10]), but all of them require an additional separation unit for $\mathrm{CO}_{2}$ capture.

As an alternative to adding a dedicated capture unit, we have recently developed several vacuum pressure swing adsorption (VPSA) cycles, that integrate $\mathrm{H}_{2}$ purificationthus replacing the PSA-and $\mathrm{CO}_{2}$ capture, within a single separation unit. Such combined processes were examined in the past [11, 12], but they relied on two interconnected trains, each undergoing a completely different cycle 
sequence for regeneration. The VPSA cycles we have developed avoid this and achieve the co-purification of $\mathrm{CO}_{2}$ and $\mathrm{H}_{2}$ at high purities and recoveries in a single cycle for typical shifted SMR syngases [13, 14]. In this series, we present the complementary experimental work to our modeling studies.

In part one [15], we focus on equilibrium isotherm measurements and breakthrough studies to estimate transport parameters, identify a suitable heat transfer model, and validate our column model for relevant mixtures and a variety of temperatures, pressures and flow rates. In this second part, we present cyclic experiments carried out in the same two-column setup for a ternary $\mathrm{CO}_{2}-\mathrm{H}_{2}-\mathrm{CH}_{4}$ stream as feed and using zeolite $13 \mathrm{X}$ as adsorbent. The goals of this paper are (i) to further validate the model used for process development and optimization; (ii) to demonstrate the technology at the lab-scale, thus showing the feasibility of reaching CCS requirements (>90\% $\mathrm{CO}_{2}$ recovery, $>96 \%$ $\mathrm{CO}_{2}$ purity, [16, 17]) whilst co-purifying $\mathrm{H}_{2}$ up to high purities (> 99.9/99,97\%, depending on the application, [6]); and (iii) to assess the effect of important decision variables on the separation performance. We hope that this demonstration will encourage further development and studies into industrial application of VPSA, thus facilitating the emergence of $\mathrm{H}_{2}$ production with CCS.

The paper starts with an overview of the experimental and simulation tools used in this work. Subsequently, we present and discuss the cycle and the experimental results based on a reference experiment. This is followed by a detailed comparison between experimental measurements and simulation results for a second reference experiment. Finally, the effect of different decision variables and and of the cycle configuration is presented and discussed.

\section{Experimental and simulation tools}

\subsection{Experimental setup}

The experimental setup used for the VPSA experiments is based on the two column setup described in [18]. A simplified flow sheet is shown in Fig. 1 with the changes compared to the previous setup highlighted in red and blue.

The core of the setup consists of two double-jacketed columns that are externally heated/cooled with two thermostates (Huber Kältemaschinenbau AG, Germany) as explained in detail in the aforementioned paper. To measure the column conditions, 5 thermocouples (Moser TMT AG, Switzerland) are positioned in the center $(r=0)$ of both columns at 10, 35, 60, 85 and $110 \mathrm{~cm}$ from the column bottom. The pressure is measured with pressure sensors (Keller, Germany) at column top and bottom. Additional flexibility was added with two additional inlet lines coupled with two new

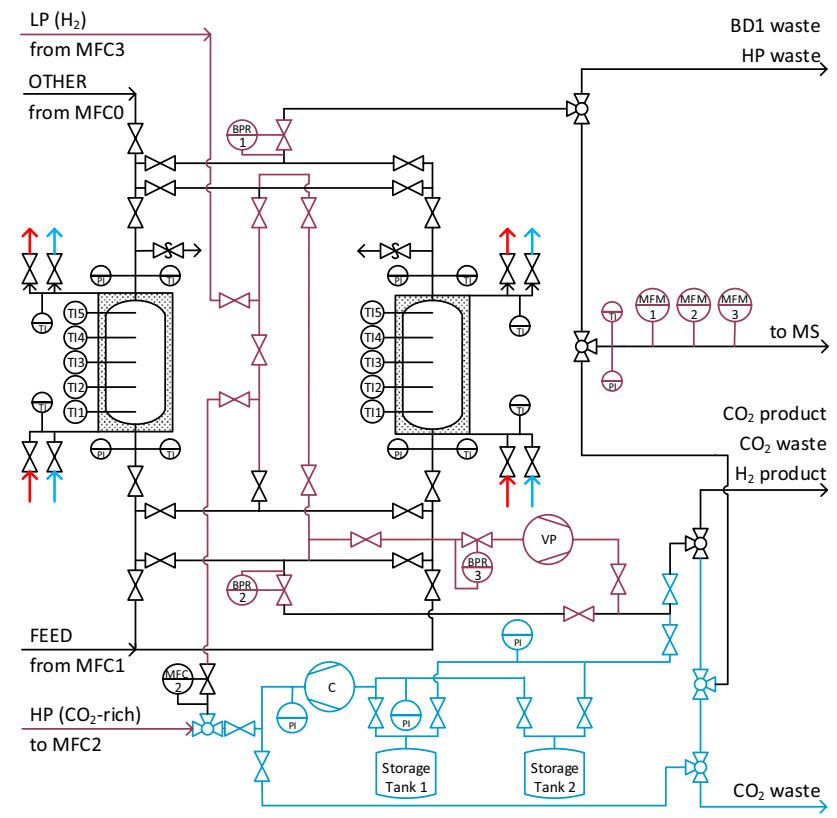

Fig. 1 Experimental setup for VPSA experiments, red and blue lines highlight the changes compared to the setup described in [18] (Color figure online)

mass flow controllers (MFCs), that allow for a higher and a lower flow than previously possible (Bronkhorst High-Tech BV, the Netherlands). In addition, the old back pressure regulators (BPRs) were replaced by BPRs suitable for the new pressures and flow rates (Bronkhorst High-Tech B.V.). An additional BPR for the sub-atmospheric pressures together with a new exit line and a new vacuum pump (VP, Pfeiffer Vacuum Schweiz AG, Switzerland) were added to control the pressure during evacuation and sub-atmospheric purge. As previously discussed in the literature [18, 19], metering the flow in temperature and pressure swing applications is difficult, as flows over several orders of magnitude have to be metered. Therefore, we replaced the rotameters used in the past with three mass flow meters (MFM) in series (Bronkhorst High-Tech B.V.), thus spanning a flow range of four orders of magnitude. Downstream of the MFMs, the outflow composition is measured using a mass spectrometer (MS, Pfeiffer Vacuum Schweiz AG). The setup dimensions are reported in Table 1.

In addition to those changes, the setup was extended to include a recycle section shown in blue in Fig. 1. The recycle section can be connected to the outflow of the columns either after VP or BPR 2. The outflow can be stored in one or both of the two storage tanks ( $10 \mathrm{~L}$ commercial gas bottles) and recycled through MFC 2 as feed to one of the two columns using a VP/compressor combination (C, KNF Neuberger AG, Switzerland). With this configuration, the pressure in the storage tanks alternates between ambient pressure (or below) and the lowest vacuum the pump can achieve. 
Table 1 Setup dimensions, transport parameters and material properties

\begin{tabular}{|c|c|c|}
\hline Parameter & Symbol [Unit] & Value \\
\hline Particle diameter & $d_{\mathrm{p}}[\mathrm{m}]$ & 0.0018 \\
\hline Sceletal density & $\rho_{\mathrm{s}}\left[\mathrm{kg} / \mathrm{m}^{3}\right]$ & 2359 \\
\hline Particle density & $\rho_{\mathrm{p}}\left[\mathrm{kg} / \mathrm{m}^{3}\right]$ & 1085 \\
\hline Bed density & $\rho_{\mathrm{b}}\left[\mathrm{kg} / \mathrm{m}^{3}\right]$ & 595 \\
\hline Thermofluid temperature & $T_{\mathrm{amb}}\left[{ }^{\circ} \mathrm{C}\right]$ & 25 \\
\hline Heat capacity sorbent & $C_{\mathrm{s}}[\mathrm{J} / \mathrm{kg} / \mathrm{K}]$ & 1100 \\
\hline Inner column diameter & $d_{\mathrm{i}}[\mathrm{m}]$ & 0.025 \\
\hline Outer column diameter & $d_{\mathrm{o}}[\mathrm{m}]$ & 0.03 \\
\hline Column length & $L_{\mathrm{col}}[\mathrm{m}]$ & 1.2 \\
\hline Heat capacity wall & $C_{\mathrm{w}}[\mathrm{J} / \mathrm{kg} / \mathrm{K}]$ & $4 \times 10^{6}$ \\
\hline Viscosity gas mixture & $v[\mathrm{~kg} / \mathrm{m} / \mathrm{s}]$ & $\begin{array}{r}1.38 \times \\
10^{-5}\end{array}$ \\
\hline Coeff. P-decrease BD ${ }^{\mathrm{a}}$ & $\xi_{\mathrm{BD}}[1 / \mathrm{s}]$ & 0.43 \\
\hline Coeff. P-decrease BD-vac ${ }^{\mathrm{a}}$ & $\xi_{\mathrm{BD}-\mathrm{vac}}[1 / \mathrm{s}]$ & 0.05 \\
\hline Heat transfer convective ${ }^{b}$ & $h_{\mathrm{c}}\left[\mathrm{W} / \mathrm{m}^{2} / \mathrm{K}\right]$ & 60 \\
\hline Heat transfer stagnant ${ }^{c}$ & $h_{\mathrm{i}}\left[\mathrm{W} / \mathrm{m}^{2} / \mathrm{K}\right]$ & 34 \\
\hline Heat transfer $\mathrm{LP}^{\mathrm{d}}$ & $h_{\mathrm{LP}}\left[\mathrm{W} / \mathrm{m}^{2} / \mathrm{K}\right]$ & 19 \\
\hline External heat transfer ${ }^{\mathrm{e}}$ & $h_{\mathrm{w}}\left[\mathrm{W} / \mathrm{m}^{2} / \mathrm{K}\right]$ & 220 \\
\hline
\end{tabular}

${ }^{a}$ Fitted to base-case cyclic experiments

${ }^{\mathrm{b}}$ Calculated according to [20] based on base case feed composition, pressure and flow rate

${ }^{c}$ Calculated according to [20] based on base case feed composition, pressure and zero flow

${ }^{\mathrm{d}}$ Calculated according to [20] based on base case LP pressure, inlet flow rate and $\mathrm{CO}_{2}: \mathrm{H}_{2}=90: 10 \mathrm{~mol} \%$ in approximation of the LP outlet composition

${ }^{\mathrm{e}}$ As reported in [18] for the same columns and thermostats

The whole setup is automated in LabVIEW (National Instruments, USA) to ensure a reproducible operation of the cycle sequence. Note that the outflow flow rate and composition can be measured either after BPR 2 and the vacuum pump, or after BPR 1, depending on the position of the manual three-way valves.

Experimental procedure Before the first experiment, the adsorbent was regenerated overnight at a temperature of 240 ${ }^{\circ} \mathrm{C}$ whilst drawing a vacuum. This ensures that all adsorbed water is desorbed. Prior to each experiment or set of two experiments in a row, the MS was calibrated using the feed mixture and at least one additional mixture. Subsequently, the column was pre-saturated to ensure an initial state that is close to the final state, first with the feed mixture at 25 bar until the temperature front related to $\mathrm{CO}_{2}$ adsorption reached the middle of the column, then at ambient pressure with the heavy purge mixture until the $\mathrm{CO}_{2}$ thermal front reached the fifth thermocouple, and finally evacuated and purged with $\mathrm{H}_{2}$. This procedure drastically reduced the number of cycles needed to reach steady state from around 50 cycles to $15-30$ cycles. Cyclic steady state (CSS in short) was verified by checking that the composition and temperature profiles for five subsequent cycles do not change. Considering experimental uncertainties, this implies that any variation of these properties is below the limit of detection. Note, however, that over the course of many cycles those non-detectable variations could potentially sum up and lead to significant differences in performance. We have verified that this does not happen by extending both experiments and simulations beyond the point when the experimental criterion for CSS has been attained. Overall, we found composition profiles to be the better indicator, as the temperatures fronts cannot track little changes in the position of the $\mathrm{CH}_{4}$ or the $\mathrm{H}_{2}$ front, due to their low heat of adsorption. Once CSS was reached, first the outflow from BPR 2 (Ads step, Fig. 2) and VP (BD-vac and LP steps, Fig. 2) were measured for a few cycles, and subsequently the valves were switched manually and the outflow from BPR 1 (BD and HP steps, Fig. 2) was measured for a few cycles.

In case two experiments were carried out one after the other, the second experiment was started directly after the first, without any intermediate regeneration, thus resulting in an even faster convergence to CSS. After a maximum of two experiments, the column was regenerated completely for a minimum of two hours at a temperature of $240{ }^{\circ} \mathrm{C}$ whilst drawing vacuum.

\subsection{Materials}

For all experiments, zeolite 13X (Zeochem, Switzerland) with a pellet size between 1.6 and $2 \mathrm{~mm}$ was used. The relevant material properties are reported in Table 1. All pure gases and gas mixtures were obtained from Pangas (Switzerland) as indicated in Table 3.

\subsection{Modeling}

Process modeling In this work, the same one dimensional model based on mass and energy balance equations as described in part one of this series [15] was used for comparing experimental and simulation results. The gas phase was described using the ideal gas law, the pressure drop was described with the Ergun equation. Constant, average values were used for the heats of adsorption, the viscosity of the gas phase and the mass transfer coefficients, with mass transfer being described using a linear driving force approximation. Diffusion was neglected. All required input parameters are provided in Tables 1 and 2.

During pressure equalization (PE) steps, the final pressure was calculated iteratively based on a closed mass balance where the outflow equals the inflow as described in the literature [21]. The internal heat transfer coefficient was calculated for the feed conditions based on a correlation by Specchia 
et al. [20] (Table 1). In part one of this series [15], we found that this correlation results in a good agreement between measurements during breakthrough experiments and simulations.

Adsorption equilibria The single component adsorption isotherms of $\mathrm{CO}_{2}, \mathrm{CH}_{4}$ and $\mathrm{H}_{2}$ on zeolite $13 \mathrm{X}$ were measured in previous works $[22,15]$ and fitted to a Sips isotherm model (Eq. 1).

$q_{i}=q_{i}^{\infty}(T) \frac{\left(b_{i}(T) P_{i}\right)^{s_{i}}}{1+\left(b_{i}(T) P_{i}\right)^{s_{i}}}$

The isotherm parameters are summarized in Table 2.

For modeling multi-component adsorption, three different approaches were followed, namely the use of extended isotherms, the real adsorbed solution theory (RAST), and the ideal adsorbed solution theory (IAST). For RAST, the Wilson equation was used to model the activity coefficients, including the temperature dependency suggested by Wilson [23] for the binary interaction parameters $\Lambda_{i j}$ :

$\Lambda_{i j}=\frac{v_{j}}{v_{i}} \exp \left(-\frac{\lambda_{i j}-\lambda_{i i}}{R T}\right)=\frac{v_{j}}{v_{i}} \exp \left(-\frac{\overline{\lambda_{i}}}{R T}\right)$

The $i, j$-interaction energies $\lambda_{i j}$, or directly the difference $\overline{\lambda_{i}}$, have to be fitted to experimental data. To reduce the number of fitting parameters, we first set all $\Lambda_{i j}$ equal to unity for all binary mixtures with hydrogen (thus reducing RAST to IAST for binary $\mathrm{H}_{2}$ mixtures). Second, we assumed that the interaction energy between $\mathrm{CO}_{2}$ and $\mathrm{CH}_{4}$ is given by the mean of the interaction energies between the individual species, as described in the literature by [22]. This results in $\overline{\lambda_{i}}=-\bar{\lambda}_{j}$ for $\mathrm{CO}_{2}-\mathrm{CH}_{4}$ mixtures. Thus, only one parameter has to be fitted to the cyclic experiments (see also part one of this series, [15]).

\subsection{Data reconciliation}

When evaluating the experiments and for comparing experimental and simulation results, the following factors have to be considered:

1. Measurement errors

2. Idle times (required to synchronize PE steps)

3. Piping

(a) The downstream piping results in a time delay between the column outlet and the composition measured at the MS, that depends on flow and pressure

(b) Due to this time delay, the composition of last part of a product or tail gas is not measured during the step itself; instead, it remains in the downstream piping and is measured only as contamination during the first few seconds of the next measured outflow

(c) The pressure change during pressurization/blowdown steps depends on upstream/downstream piping

(d) Many pipes are shared for different steps, thus leading to mixing of in-and outflows at different pressures and compositions within these pipes

Only points 1 and $3 \mathrm{~b}$ were considered for evaluating the experimental results. Because the calculation of key performance indicators requires a combination of the measurements of various sensors, we evaluated how the measurement error propagates to those final results assuming normally distributed, uncorrelated measurement errors. The errors of MFMs and MFCs ( $2 \%$ of full scale), of the MS (due to calibration) and the error of Feed and HP composition (Table 3) were included. The influence of the composition error on the calculation of the gas conversion factor for the MFMs was not included (point 1).

The effect of point $3 \mathrm{~b}$ is significant because of the large piping volume compared to small columns, and large pressure differences between different steps, but specific to our setup. For industrial applications, it could be avoided through the use of dedicated outlet lines or purging/evacuation of the lines before the next step. Thus, we correct for it when evaluating the experiments and for comparing experimental and simulation results (point $3 \mathrm{~b}$ )

For comparing experiments and simulations, also the other points were considered. To provide a better representation of the experimental results, idle steps were included in the simulation allowing for heating or cooling and adsorption or desorption, but neither in- nor outflow. During idle times and LP, heat transfer is much lower than during the

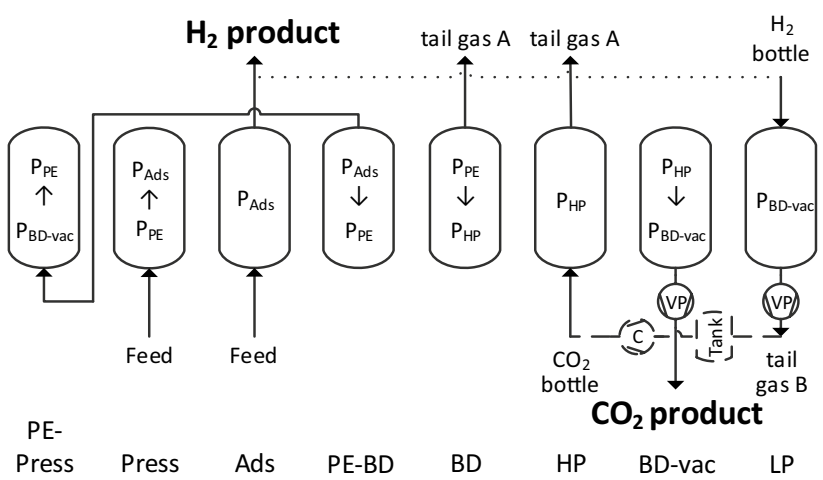

Fig. 2 VPSA cycle for co-purification of $\mathrm{H}_{2}$ and $\mathrm{CO}_{2}$. Dashed and dotted lines indicate the targeted implementation in a real plant, whereas for the lab-pilot tests, rather than having two recycles, $\mathrm{H}_{2}$ and $\mathrm{CO}_{2}$ gas bottles were used to emulate the recycle streams for all but Exp. 10. Exp. 10 includes the recycle of tail gas B indicated with dashed lines 
Table 2 Isotherm parameters and mass transfer coefficients

\begin{tabular}{|c|c|c|c|c|c|c|}
\hline \multirow[t]{2}{*}{ Parameter } & \multirow[t]{2}{*}{ Equation } & \multirow[t]{2}{*}{ Symbol } & \multirow[t]{2}{*}{ Unit } & \multicolumn{3}{|l|}{ Value } \\
\hline & & & & $\mathrm{CO}_{2}$ & $\mathrm{H}_{2}$ & $\mathrm{CH}_{4}$ \\
\hline \multirow[t]{2}{*}{ Maximum capacity $q_{i}^{\infty}$} & \multirow{2}{*}{$q_{i}^{\infty}(T)=A_{1, i} \exp \left(A_{2, i}\left(\frac{T}{T_{\text {ref }}}-1\right)\right)$} & $A_{1, i}$ & $\mathrm{~mol} / \mathrm{kg}$ & 7.268 & 5.013 & 4.473 \\
\hline & & $A_{2, i}$ & - & -0.61684 & 0 & -0.6569 \\
\hline \multirow[t]{2}{*}{ Affinity coefficient $b_{i}$} & \multirow[t]{2}{*}{$b_{i}(T)=B_{1, i} \exp \left(\frac{B_{2, i}}{R T}\right)$} & $B_{1, i}$ & bar $^{-1}$ & $1.129 \mathrm{e}-4$ & $1.034 \mathrm{e}-4$ & $3.605 e-4$ \\
\hline & & $B_{2, i}$ & $\mathrm{~kJ} / \mathrm{mol}$ & 28.389 & 9.453 & 15.561 \\
\hline \multirow[t]{2}{*}{ Sips exponent $s_{i}$} & \multirow[t]{2}{*}{$s_{i}(T)=C_{1, i}+C_{2, i} \exp \left(\frac{T}{T_{\mathrm{ref}}}-1\right)$} & $C_{1, i}$ & - & 0.42456 & 1.0057 & 1.0727 \\
\hline & & $C_{2, i}$ & - & 0.72378 & 0 & 0 \\
\hline Reference temperature & & $T_{\text {ref }}$ & ${ }^{\circ} \mathrm{C}$ & 25 & 25 & 25 \\
\hline Heat of adsorption ${ }^{\mathrm{a}}$ & & $\Delta H_{\text {iso }}$ & $\mathrm{kJ} / \mathrm{mol}$ & -34.2 & -10.7 & -17.5 \\
\hline Mass transfer coefficient ${ }^{b}$ & & $k_{i}$ & $1 / \mathrm{s}$ & 0.06 & 1 & 0.2 \\
\hline
\end{tabular}

${ }^{a}$ Averaged up to the loading corresponding to maximum partial pressures reached in the VPSA, hence slightly lower than for part one of this series, where it was average over the whole loading range measured [15]

${ }^{b}$ Fitted to breakthrough experiments, part one of this series [15]

other steps (due to the low mass flow), such that we used different heat transfer coefficients calculated specifically for these steps according to [20] (Table 1) (point 2).

During the pressure changing steps (Press, BD, BD-vac, see Fig. 2), the boundary conditions at the column bottom (Press, BD-vac, see Fig. 2) or column top (BD, see Fig. 2) were described with a linear pressure increase for Press, and with an exponential pressure decrease for BD and BD-vac:

$P=P_{\text {low }}+\left(P_{\text {high }}-P_{\text {low }}\right) \exp (-\xi t)$

based on the experimental results. This approach is easy to implement and allows for a good representation of the actual inflow into (outflow out of) the column without having to include a mathematical description of setup specific conditions like dead volumes, valves or flow resistances of piping or BPRs. Note that the setpoint vacuum pressure was not reached during all experiments and for simulation purposes $P_{\text {low }}$ was set to the actual lowest pressure reached at the end of BD-vac with a further, linear pressure decay to the final pressure during LP (point $3 \mathrm{c}$ ).

When comparing experimental and simulation results, a direct comparison is difficult for both flow and composition due to the dead volumes in the experimental setup. The influence of the downstream piping is difficult to assess in modeling, and different approaches have been used in the literature including the modeling of the piping as plug flow [15], as tanks in series [24], or through the insertion of a stagnant tank as part of the piping to account for non-purged parts [19]. In this work, we did not simulate the downstream piping, as the exact conditions of the dead volume (pressure, composition and temperature) would be required. These conditions change from step to step and are particularly cumbersome to determine for this cycle, because many pipes are shared for some steps, but not for others resulting in complex mixing patterns of the gas phase in the pipes (point $3 \mathrm{~d}$ ). Thus, we base our comparison between experiments and simulations mainly on the temperature profiles, that are measured without time delay.

In addition, we included an lower bound estimate of the time shift between the column outlet and the measurement at the MS based on isothermal (at $T=25^{\circ} \mathrm{C}$ ) plug flow conditions in the piping — as in part one of this series — and the current outflow. For steps at or above ambient pressure, we assume the part of the piping until the BPR to be at column outlet pressure, and the part after at ambient pressure. For steps below ambient pressure that use VP, the piping between BPR and VP was neglected (assuming it to be fully evacuated) and only the part after VP was included. This estimate of the time shift allows to assess for which part of the cycle the concentration measurements are reliable, and for which they are not (point $3 \mathrm{a}$ ).

\section{VPSA demonstration}

\subsection{VPSA cycle}

We have previously developed different VPSA cycles for the co-purification of $\mathrm{CO}_{2}$ and $\mathrm{CH}_{4}$ based on process modeling and

Table 3 Composition of pure gases and gas mixtures

\begin{tabular}{lllll}
\hline & $\begin{array}{l}\mathrm{H}_{2} \\
\mathrm{~mol} \%\end{array}$ & $\begin{array}{l}\mathrm{CO}_{2} \\
\mathrm{~mol} \%\end{array}$ & $\begin{array}{l}\mathrm{CH}_{4} \\
\mathrm{~mol} \%\end{array}$ & Notes \\
\hline LP & 100 & 0 & 0 & 5.0 \\
HP pure & 0 & 100 & 0 & 3.0 \\
HP mix & $8 \pm 0.08$ & $90 \pm 0.12$ & $2 \pm 0.04$ & \\
Feed mix 1 & $75 \pm 0.3$ & $20 \pm 0.2$ & $5 \pm 0.1$ & \\
Feed mix 2 & $72.5 \pm 0.35$ & $20 \pm 0.2$ & $7.5 \pm 0.15$ & \\
\hline
\end{tabular}

Relative errors as provided by manufacturer. The different gas bottles are used for different cycle steps, see Sect. 3 
optimization [13, 14]. A simplified version of the best-performing cycle was selected for the experimental demonstration and is shown in Fig. 2. As feed stream, a ternary mixture representative of typical shifted SMR gases was used. It consists of the two target products and of methane as the impurity (Feed mix $1 / 2$, Table 3). Note that typical shifted SMR gas also contains water, which adsorbs stronger then $\mathrm{CO}_{2}$ on common adsorbents like activated carbons and zeolites. Water can be dealt with in two ways. It is possible to remove it within VSA or PSA cycles, typically by using layered beds with the first layer adsorbing most or all of the water [25, 26, 12]. Alternatively, one can dry the feed before entering the adsorption cycle. In this work, we have adopted the second approach and have used a dry feed. All operating parameters are summarized in Sect. 5.

In the simplified configuration implemented in our lab-pilot (solid lines, Fig. 2), both $\mathrm{H}_{2}$ for the $\mathrm{LP}$ and $\mathrm{CO}_{2}$ for the HP were provided from gas bottles. For implementing the cycle at large scale, however, both streams should be recycled from within the cycle as indicated in Fig. 2 with dashed and dotted lines and as assumed in the previous theoretical studies [13, 14]. Note that emulating the recycled $\mathrm{H}_{2}$ product with a gas bottle (dotted lines) is a good representation of the cycle with recycle, because (i) little $\mathrm{H}_{2}$ is needed for this step and (ii) it is produced at very high purity. Using pure $\mathrm{CO}_{2}$ for the inlet to $\mathrm{HP}$, however, is a big simplification, because the LP outflow does not provide pure $\mathrm{CO}_{2}$; the implications of this simplification are discussed in Sect. 5 .

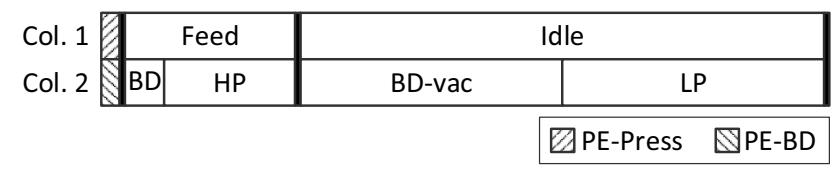

Fig. 3 Schedule for Exp. 1 (see Table 5), half cycle. After the end of the first half cycle, the half cycle shown for column 1 is repeated in column 2 , and vice versa

For implementing the VPSA cycle (Fig. 2) in the two column lab-pilot (Fig. 1), scheduling is required to synchronize the PE step. The schedule for Exp. 1 is shown in Fig. 3. Due to the long duration of BD-vac and LP, long idle times are needed after the end of the Feed step. During idle times, the column was closed, but continued to exchange heat with the surrounding.

\subsection{Profiles at cyclic steady state}

Figure 4 shows the pressure (a), temperature (b), flow (Fig.) and composition (d, e) profiles measured for Exp. 1 at CSS. The corresponding step times are provided in Tables 4 and 5.

The column is pressurized first through pressure-equalization (PE-Press) followed by a feed pressurization (Press) until the adsorption pressure of 25 bar is reached (Fig. 4a). At this point, the BPR connected to the column top opens and high purity $\mathrm{H}_{2}$ is produced as light product and at a roughly constant flow rate (Fig. $4 \mathrm{c}$, d), whilst $\mathrm{CO}_{2}$ and
Table 4 Operating conditions for all experiments

\begin{tabular}{llllllll}
\hline & $t_{\mathrm{PE}}$ & $t_{\mathrm{BD}}$ & $t_{\mathrm{BD}-\mathrm{vac}}$ & $t_{\mathrm{LP}}$ & $\dot{V}_{\text {Feed }}$ & $P_{\mathrm{HP}}$ & $P_{\text {Ads }}$ \\
\hline Unit & $\mathrm{s}$ & $\mathrm{s}$ & $\mathrm{s}$ & $\mathrm{s}$ & $10^{-5} \mathrm{~m}^{3} / \mathrm{s}^{\mathrm{a}}$ & bar & bar \\
Value & 7 & 15 & 100 & 100 & 2 & 1 & 25 \\
\hline
\end{tabular}

${ }^{\mathrm{a}}$ At 25 bar and $25^{\circ} \mathrm{C}$

Table 5 Operating conditions specific to different cyclic experiments; changes compared to the respective base case are highlighted in grey

\begin{tabular}{|c|c|c|c|c|c|c|c|}
\hline \multirow{2}{*}{ Exp. \# } & ${ }^{t} \mathrm{HP}$ & ${ }^{t}$ Feed & $\dot{V}_{\mathrm{LP}}$ & $\dot{V}_{\mathrm{HP}}$ & $P_{\text {vac }}$ & Feed & $\mathrm{HP}$ \\
\hline & $\mathrm{s}$ & $\mathrm{s}$ & $10^{-5} \mathrm{~m}^{3} / \mathrm{s}^{\mathrm{a}}$ & $10^{-5} \mathrm{~m}^{3} / \mathrm{s}^{\mathrm{b}}$ & bar & $\begin{array}{c}\mathrm{mol} \% \\
\mathrm{CH}_{4}: \mathrm{CO}_{2}: \mathrm{H}_{2}\end{array}$ & $\begin{array}{c}\mathrm{mol} \% \\
\mathrm{CH}_{4}: \mathrm{CO}_{2}: \mathrm{H}_{2}\end{array}$ \\
\hline \multirow{2}{*}{$\begin{array}{l}1 \text { Base case A } \\
2\end{array}$} & \multirow{2}{*}{$\begin{array}{l}50 \\
50\end{array}$} & \multirow{2}{*}{$\begin{array}{l}65 \\
65 \\
\end{array}$} & 2 & \multirow{2}{*}{$\begin{array}{l}4 \\
4\end{array}$} & \multirow{2}{*}{$\begin{array}{c} \\
0.14 \\
0.14\end{array}$} & $5: 20: 75$ & $0: 100: 0$ \\
\hline & & & 6 & & & $5: 20: 75$ & 0:100:0 \\
\hline 3 Base case B & 65 & 65 & 2 & 4 & 0.14 & $5: 20: 75$ & 0:100:0 \\
\hline 4 & 65 & 65 & 6 & 4 & 0.14 & $5: 20: 75$ & 0:100:0 \\
\hline 5 & 65 & 80 & 2 & 4 & 0.14 & $5: 20: 75$ & 0:100:0 \\
\hline 6 & 65 & 65 & 2 & 4 & 0.11 & $5: 20: 75$ & 0:100:0 \\
\hline $7^{\mathrm{c}}$ & 65 & 65 & 2 & 4 & 0.17 & $5: 20: 75$ & 0:100:0 \\
\hline 8 & 65 & 65 & 2 & 4 & 0.14 & $7.5: 20: 72.5$ & $0: 100: 0$ \\
\hline 9 & 65 & 65 & 2 & 4 & 0.14 & 5:20:75 & $2: 100: 8$ \\
\hline 10 & 65 & 65 & 2 & - & 0.14 & $5: 20: 75$ & - \\
\hline
\end{tabular}

\footnotetext{
a at 0.1 bar and $25^{\circ} \mathrm{C}$

$\mathrm{b}$ at $1 \mathrm{~atm}$ and $25^{\circ} \mathrm{C}$

${ }^{c}$ two repetitions
} 
Fig. 4 Pressure (a), temperature (b), flow (c) and composition (d,e) profiles for experiment 1 . Squares and asterisks indicate two different, non-consecutive cycles at CSS. Pressure and temperature profiles are shown for column 1 . The composition was measured from the bottom outlet for several cycles in a row (d, corresponding to Ads, BD-vac and LP), and subsequently from the top outlet (e, corresponding to BD1 and HP). The composition corresponding to the outflow of column 1 is indicated with symbols in (d) and (e). Also the flow was measured first from the bottom and subsequently from the top outlet line, but the outflow corresponding to column 1 only is indicated. Thus, graph (c) corresponds to four different cycles at CSS. During PE-steps and idle steps, no outflow is measured and the composition is the same as measured before, the corresponding composition is indicated with dashes (corresponding to squares) and dotted (corresponding to asterisks) (Color figure online)

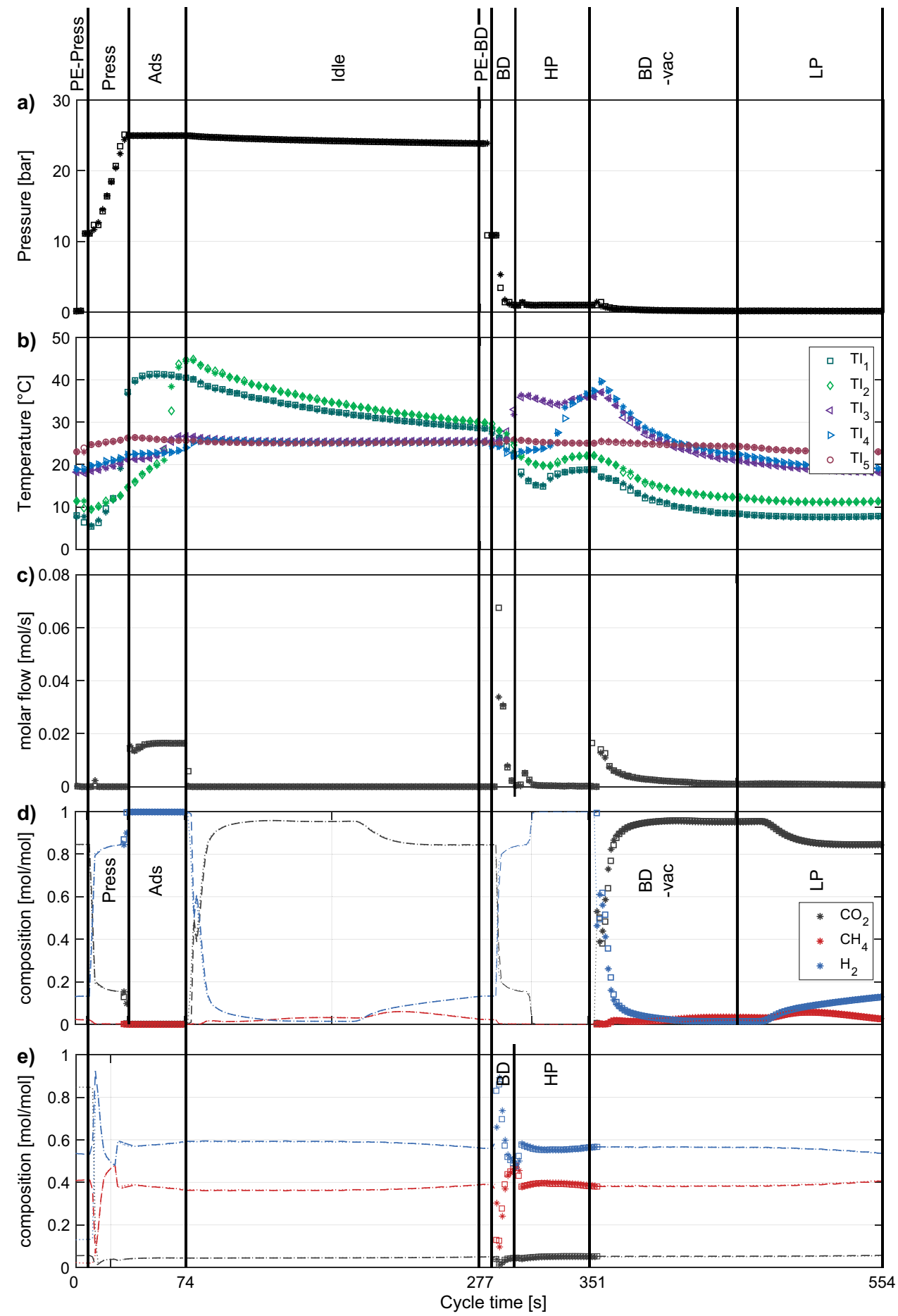

impurity are adsorbed in the column (Ads). The propagation of the $\mathrm{CO}_{2}$ adsorption front through the column during Press and Ads results in the propagation of a corresponding temperature front (TI 1 and TI 2, Fig. 4b). Before $\mathrm{CH}_{4}$ breaks through, $\mathrm{H}_{2}$ production is stopped. The column remains idle for $\approx 200 \mathrm{~s}$ and cools down to the thermofluid temperature $\left(25^{\circ} \mathrm{C}\right)$. This cooling results in a pressure decrease, and also in further adsorption due to the lower temperature, thereby intensifying the decrease in pressure (Fig. 4a, b).

Once the first half-cycle is finished, the pressure inside the column is reduced through pressure-equalization (PEBD, Fig. 4a) followed by a blowdown (BD) from the column-top to ambient pressure. The resulting desorption leads to a temperature decrease, whilst pressure and outflow decrease exponentially (Fig. 4a-c). A tail gas initially 
rich in $\mathrm{H}_{2}$, with increasing amounts of impurity and little $\mathrm{CO}_{2}$, is produced (Fig. 4e). Next, a purge with $\mathrm{CO}_{2}$ (the heavy product, heavy purge $\mathbf{H P}$ ) is carried out to enrich the column in $\mathrm{CO}_{2}$ (gas and adsorbed phase). The temperature increases in the top half of the column due to $\mathrm{CO}_{2}$ adsorption (TI 3 and TI 4, Fig. 4b). More tail gas rich in $\mathrm{H}_{2}$ and impurity with some $\mathrm{CO}_{2}$ is produced as outflow of this step (Fig. $4 \mathrm{c}$ and e). After HP, the column is evacuated from the bottom producing a stream that quickly reaches a high $\mathrm{CO}_{2}$ purity (BD-vac, Fig. 4a, c, d). The desorption can be seen clearly by means of the related temperature decrease inside the column (Fig. 4b). Subsequently, the column is purged top-down with the light product $\left(\mathrm{H}_{2}\right.$, light purge $\left.\mathbf{L P}\right)$ to desorb additional $\mathrm{CO}_{2}$ and $\mathrm{CH}_{4}$, and thus clean the column. The temperature only decreases slowly, showing that heat uptake due to desorption and heat provided through external heating almost balance each other (Fig. 4b). As outflow, a $\mathrm{CO}_{2}$-rich stream with increasing amounts of $\mathrm{H}_{2}$ breaking through is produced (Fig. 4d).

\subsection{Separation performance}

Before calculating the separation performance, point $3 \mathrm{~b}$, Sect. 2.4 has to be considered (the downstream piping is filled with product from a previous step at the beginning of the next step). Here, high pressure $\mathrm{H}_{2}$ from Ads is produced at the beginning of $\mathrm{BD}$-vac, and only replaced by the actual $\mathrm{CO}_{2}$ product after a few seconds; the same but to a lesser extent occurs at the beginning of Ads with $\mathrm{CO}_{2}$ and $\mathrm{CH}_{4}$ contaminating $\mathrm{H}_{2}$. When calculating the $\mathrm{CO}_{2}$ product purity, we account for this by subtracting the excess $\mathrm{H}_{2}$ outflow during the initial part of BD-vac (and the excess $\mathrm{CO}_{2}$ and $\mathrm{CH}_{4}$ outflow during the initial part of Ads). The subtracted molar amount is close to that expected in the known volume of piping at the given pressure and ambient temperature, which justifies the approach. With this, the purities and recoveries of both products as well as the compositions of tail gas A (BD and HP) and B (LP) can be determined.

The composition and recovery of $\mathrm{H}_{2}$ product and of $\mathrm{CO}_{2}$ product are shown over several cycles in Fig. 5.

The product compositions are essentially constant, showing that CSS is indeed reached, and the VPSA cycle separates both $\mathrm{H}_{2}$ and $\mathrm{CO}_{2}$ at high purity (Fig. 5a, b). Interestingly, the impurity of the $\mathrm{H}_{2}$ product is not $\mathrm{CH}_{4}$ starting to break through, but $\mathrm{CO}_{2}$, that could not be desorbed sufficiently from the column top during LP (Fig. 5a). The $\mathrm{H}_{2}$ recovery is rather low with $74 \%$ (Fig. $5 \mathrm{c}$ ), due to the presence of only one PE step. Increasing the number of PE steps is known to increase $\mathrm{H}_{2}$ recovery [12], but was not possible in our two-column setup. We have simulated the VPSA cycle with three PE steps, in which case $\mathrm{H}_{2}$ recoveries over $90 \%$ were obtained, in line with industrial PSA processes for $\mathrm{H}_{2}$ purification [13]. Also the recovery of $\mathrm{CO}_{2}$ is low with $72 \%$ (Fig. 5c), which is due to $\mathrm{CO}_{2}$ being wasted during the $\mathrm{LP}$ outflow, i.e. as tail gas B.

The error bars for the purities are small and lower than the deviation measured between the different half cycles. This could be due to small but correlated errors, rather than uncorrelated ones as assumed for error propagation calculations (see Sect. 2.4). To give a better approximation of the actual experimental uncertainty, we hereafter indicate the standard deviation instead of the calculated error, whenever the former exceeds the latter. The expected error is much higher for the recoveries, because their measurement is influenced by the relatively large errors of the MFMs and MFCs.

Figure $6 \mathrm{a}$ and $\mathrm{b}$ show the molar amount (a) and composition (b) of tail gas A (BD and HP). Tail gas A was measured from the top outlet line for the last two cycles only. Note that after switching to monitoring the outflow from the top outlet line in cycle 25 , the outlet line is initially filled with $\mathrm{CO}_{2}$-rich LP outflow (see Sect. 2.4, point $3 \mathrm{~b}$ ). Hence the higher $\mathrm{CO}_{2}$ and smaller $\mathrm{H}_{2}$ amount of tail gas A during the first half-cycle after switching (Fig. 6a, b). Therefore, the composition and flow computed for this half-cycle are not included in the evaluation of the average amount and composition and indicated with empty symbols.

From an overall mass balance, the expected tail gas composition and molar amount can be computed, which is indicated with asterisks and dashed lines in Fig. 6a and b up to cycle 24 . It can be seen that the computed and directly measured compositions and molar amounts agree well with each other, thus the overall mass balance closes well with deviations within the experimental uncertainty. However, the errors on the measured tail gas amount (Fig. 6a, cycle 25 and 26) are lower than the observed differences. This can be related to the difficulty of accurately measuring the outflow during the BD step with a MFM resolution of $1 \mathrm{~s}$ : the flow decreases quickly (Fig. 4c) and therefore cannot be measured precisely with such a low time resolution. We further note that the error on the calculated tail gas A composition is larger than that of any other stream, mainly because it is calculated indirectly and thus is affected by the uncertainty of all sensors.

The composition of tail gas B, i.e. the outflow of LP, is shown in Fig. 6c. The tail gas was measured together with $\mathrm{H}_{2}$ and $\mathrm{CO}_{2}$ product and is rich in $\mathrm{CO}_{2}$, but also contains significant amounts of $\mathrm{H}_{2}$ (breaking through) and some $\mathrm{CH}_{4}$. The $\mathrm{CO}_{2}$ purity reached is too low for the final $\mathrm{CO}_{2}$ product, but potentially high enough to be used as purge gas in HP instead of pure $\mathrm{CO}_{2}$ from a gas bottle. 

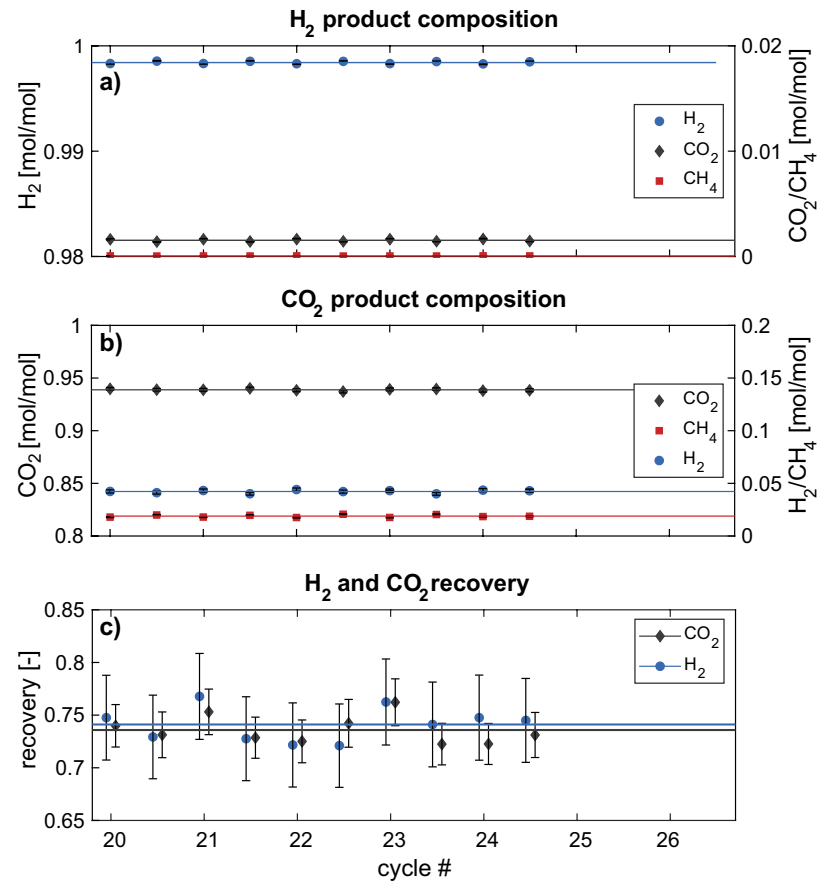

Fig. $5 \mathrm{H}_{2}$ (a) and $\mathrm{CO}_{2}$ (b) product compositions and recoveries (c) at CSS. For the last two cycles (25 and 26), the outflow was measured for BD and HP, hence the purities and recoveries could not be computed. Error bars are based on error propagation calculations

\section{Comparison between experiments and simulations}

\subsection{Profiles at cyclic steady state}

Figure 7 shows the experimentally measured (symbols) and simulated (lines) temperature (a), composition (b), pressure (c) and flow (d) profiles of Exp. 3 at CSS. RAST was used for the simulations and $\bar{\lambda}_{i}$ has been varied to best describe all experiments. A value of $4.0 \mathrm{~kJ} / \mathrm{mol}$ worked well for all cases and was used for all results shown in the following. The corresponding step times are provided in Tables 4 and 5 .

For the sake of clarity, only three temperature profiles are shown in Fig. 7a (TI 1 at $10 \mathrm{~cm}$, TI 3 at 60, and TI 5 at $110 \mathrm{~cm}$, measured from the column bottom). Simulated and experimental temperatures agree very well with each other, which shows that the model can capture heating and cooling as well as adsorption and desorption throughout the whole cycle. Also the measured and simulated pressure profiles shown in Fig. 7c agree well with each other. The flow profiles are shown in Fig. 7d, the subtracted $\mathrm{H}_{2}$ outflow from the piping at the beginning of BD-vac is indicated separately with asterisks (see Sect. 2.4, point $3 \mathrm{~b}$ and Sect. 3.3). After subtracting the $\mathrm{H}_{2}$ flow, the flow profiles match well. Note that for the first few seconds of HP, the measured outflow exceeds the simulated one. This is due to some shared piping that is still filled with higher pressure gas and connected to the column at the start of HP (refer to Sect. 2.4, point $3 \mathrm{~d}$ ).

The composition profiles are shown in Fig. $7 \mathrm{~b}$. The time delay expected between column outlet and MS (see Sect. 2.4, point 3 a) is indicated at the top of the figure. It is short during Ads and the initial part of BD and BD-vac but longer for LP and very long for HP due to lower flow rates and pressures. Hence, a comparison is meaningful mainly for Ads and BD. During these steps, the profiles compare well. For BD-vac, initially the $\mathrm{H}_{2}$ from the piping is measured, but after the measured and simulated concentrations agree well with each other, whereas for LP, the time delay results in higher measured concentrations then those simulated.

\subsection{Multicomponent adsorption}

In addition to RAST, two simpler models for multicomponent adsorption, i.e. IAST and extended isotherms, were tested. The comparison to simulation results with RAST is shown in Fig. 8a for the temperature profiles and in Fig. 8b for the composition profiles.
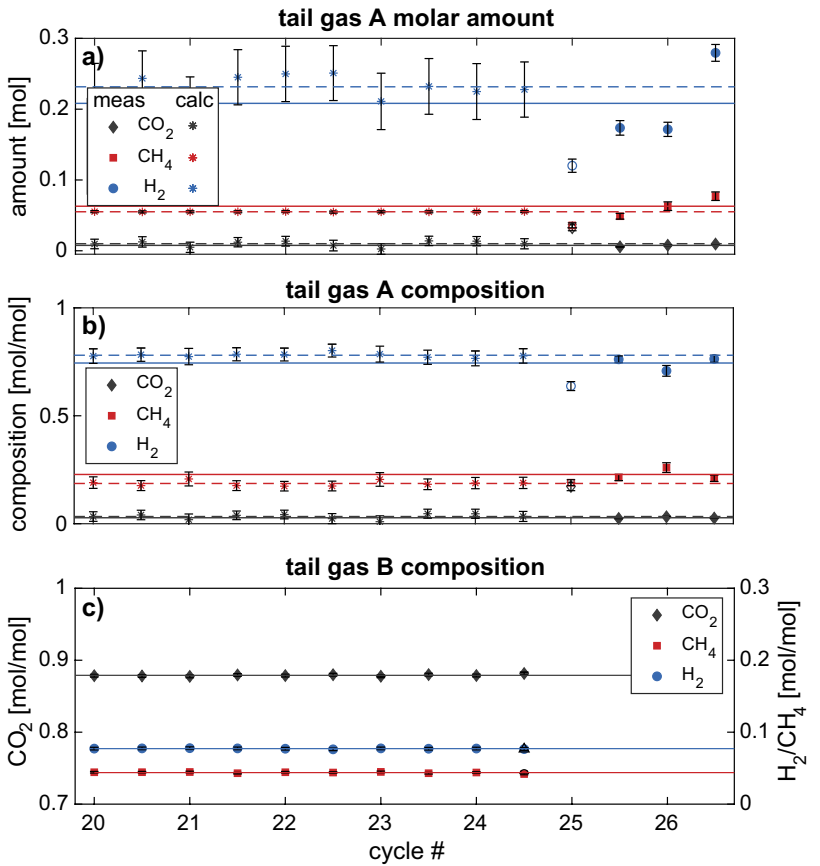

Fig. 6 a Tail gas A molar amount. b Tail gas A composition. Tail gas $\mathrm{A}$ is measured for the last two cycles only, but the composition and the molar amount are computed from an overall mass balance as indicated with asterisks and dashed lines for cycles 20-24. The first half-cycle of cycle 25 indicated with empty symbols is not included for calculating the average composition, as it is contaminated with LP outflow in the pipes after switching from monitoring the bottom outlet to monitoring the top outlet. $\mathbf{c}$ Tail gas B composition measured for all cycles except the last two. Error bars are based on error propagation calculations 


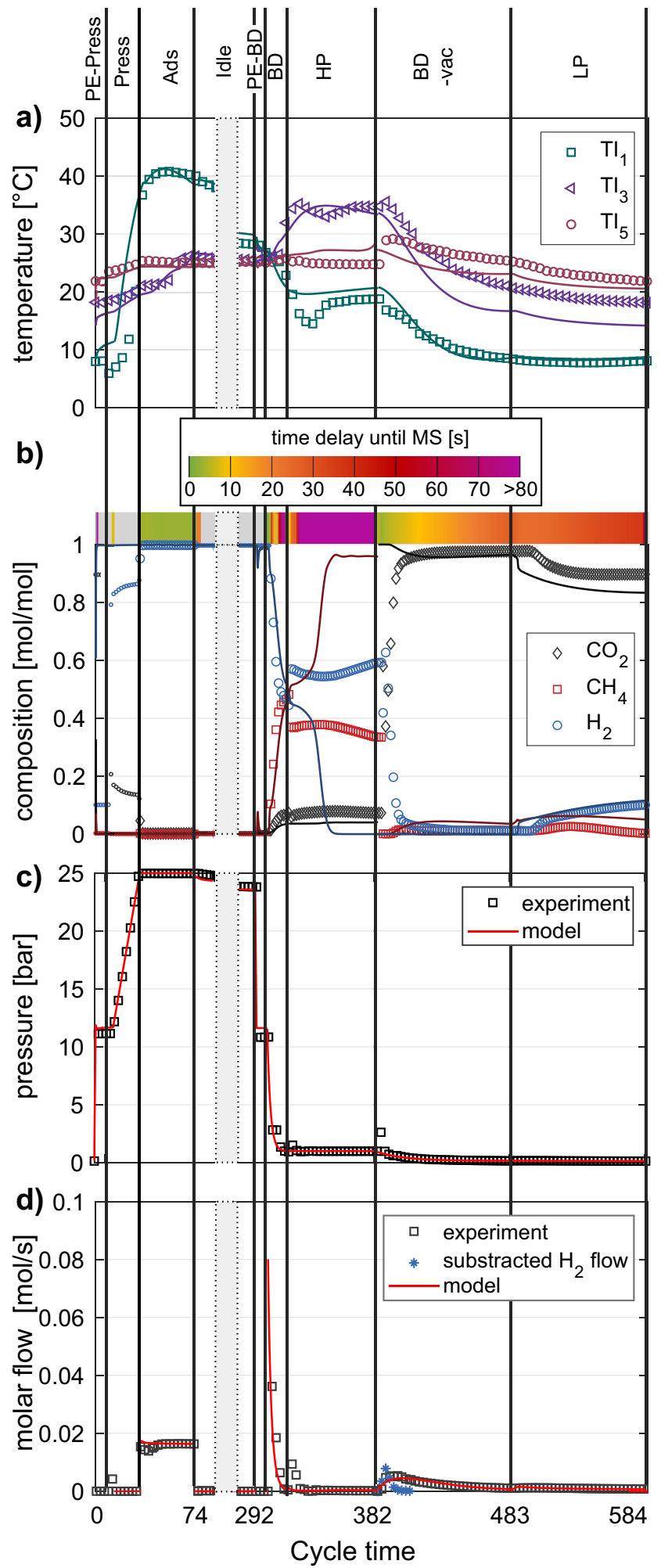

Fig. 7 Experimental (symbols) and simulated (lines) temperature (a), composition (b), pressure (c) and flow (d) profiles for Exp. 3 at CSS. Small symbols are used for the composition when there is no outflow. The time needed until the current outflow would reach the MS is color-coded to facilitate the interpretation of the concentration profiles. The $\mathrm{x}$-axis is interrupted, to show only the relevant part of the cycle and not the idle time. Simulation results for RAST using $\bar{\lambda}_{i}=4 \mathrm{~kJ} / \mathrm{mol}$ (Color figure online)

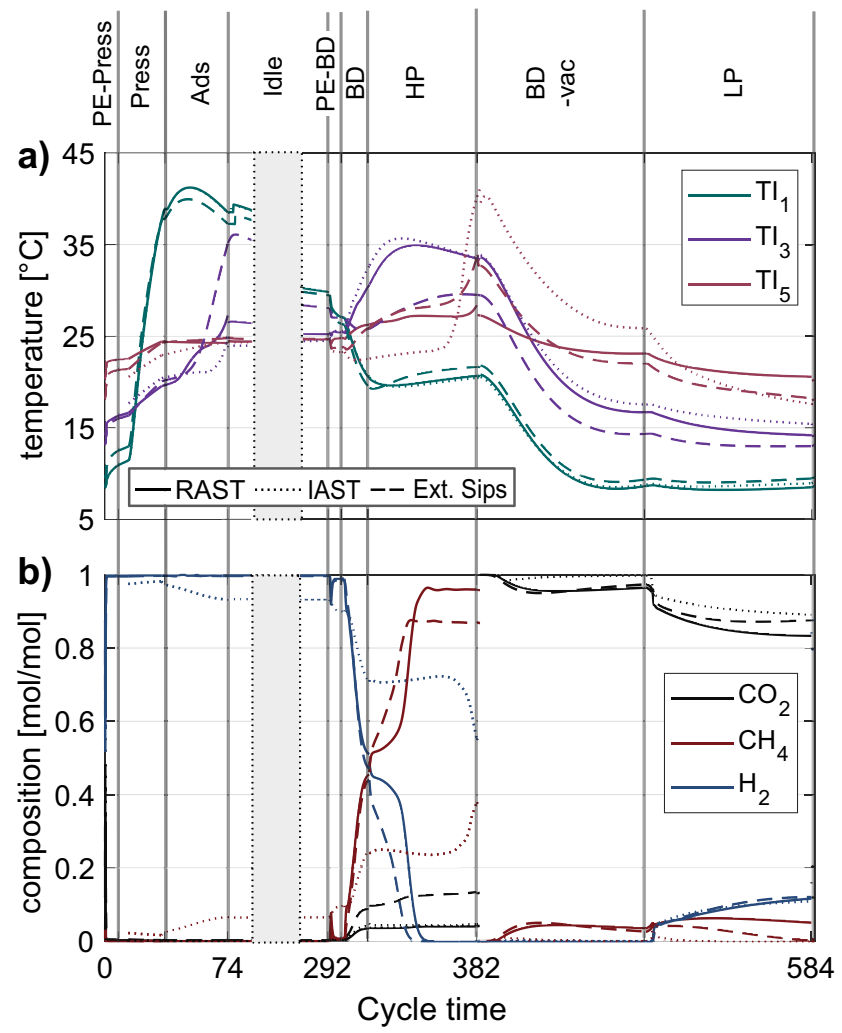

Fig. 8 Simulated temperature profiles (a) and composition profiles (b) comparing RAST (solid lines), IAST (dotted lines) and extended isotherms (dashed lines). The $\mathrm{x}$-axis is interrupted, i.e. the idle time is not shown for the sake of clarity (Color figure online)

Figure 8a shows that large deviations exist between the simulated temperature profiles obtained using RAST (solid lines) and IAST (dotted lines) on the one hand (TI3 for Ads and TI5 for HP), or RAST and extended isotherms (dashed lines) on the other hand (TI3 for Ads and HP, TI5 for HP). This means that neither IAST nor extended isotherm can predict the experimental results well; in particular the propagation of the $\mathrm{CO}_{2}$ adsorption front, that is reflected by the propagation of the temperature peaks, is not captured correctly.

The composition profiles in Fig. 8b further show that IAST predicts the production of an impure $\mathrm{H}_{2}$ product with immediate breakthrough of $\mathrm{CH}_{4}$ on the one hand, and a very pure $\mathrm{CO}_{2}$ product with barely any $\mathrm{CH}_{4}$ on the other hand, in strong contrast to the results measured. This shows that IAST does not predict $\mathrm{CH}_{4}$ co-adsorption well in this system (note that this is more difficult to detect from the temperature profiles, because of the lower adsorption and lower heat of adsorption of $\mathrm{CH}_{4}$ compared to $\mathrm{CO}_{2}$ ). Notably, extended isotherm perform much better, even though the propagation of the $\mathrm{CO}_{2}$ front is not captured well during some of the steps. The deviation between simulation results using RAST and those using extended 


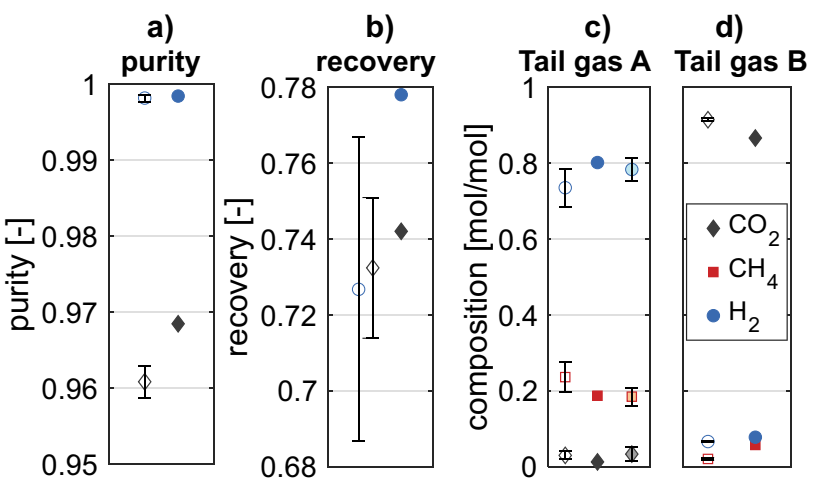

Fig. 9 Simulated (filled symbols) and experimental(empty symbols) purities (a), recoveries (b) and tail gas compositions (c and d). For the sake of visibility, they are shifted slightly apart. For Tail gas A, the composition calculated from a total mass balance and the measurement of BD, BD-vac and Ads are indicated with light filled symbols shifted slightly to the right

isotherms for those steps that allow for a meaningful comparison (i.e. Ads, BD, BD-vac) is low.

This comparison shows that a more complex theory like RAST is indeed necessary for a good agreement between experiments and simulations. A computationally expensive model like RAST, however, is less suitable for process optimization, such that other approaches are required to combine a good description of multicomponent adsorption with reasonable simulation times. One possibility is the combination of only few full model evaluations, that are then used to fit a surrogate model followed by surrogate-based optimization as described by Subraveti et al. [27].

\subsection{Performance indicators}

Figure 9a and $\mathrm{b}$ show the experimental (filled symbols) and simulated (empty symbols) purities and recoveries for Exp. 3 . The overall agreement is good, but the $\mathrm{H}_{2}$ recovery predicted by the simulations is a few percentage points lower than that measured, possibly related to the $\mathrm{H}_{2}$ remaining within the pipes after Ads (see Sect. 2.4, point $3 \mathrm{~b}$ ).

Figure $9 \mathrm{c}$ shows the measured composition of tail gas A (empty symbols for direct measurements, light filled symbols for calculations from an overall mass balance) compared to simulation results (filled symbols). The simulated results are closer to the composition calculated from an overall mass than to that measured directly. The experimentally measured $\mathrm{H}_{2}$ content is lower and $\mathrm{CH}_{4}$ as well as $\mathrm{CO}_{2}$ content higher than the simulated one. This can be explained with (i) the difficulty in measuring the outflow during the very fast BD (see Sect. 3.3) and (ii) a BD outlet pipe initially filled with HP outlet (see Sect. 2.4, point $3 \mathrm{~b}$ ), which contains less $\mathrm{H}_{2}$, but more $\mathrm{CO}_{2}$ and $\mathrm{CH}_{4}$ than $\mathrm{BD}$.
Figure 9d shows the measured composition of tail gas $\mathrm{B}$ compared to simulation results. The simulations underpredict the $\mathrm{CO}_{2}$ content and over-predicts the $\mathrm{CH}_{4}$ content. This can partially be explained by the downstream piping, i.e. the outflow originally measured during LP originates from BD-vac, and thus contains more $\mathrm{CO}_{2}$ and less $\mathrm{CH}_{4} / \mathrm{H}_{2}$ (Sect. 2.4, point $3 \mathrm{~b}$ ). The discrepancy especially in terms of the $\mathrm{CH}_{4}$ content also suggests that the multi-component adsorption model could be improved further.

\section{Effect of operating conditions and process configuration}

In this section, the effect of important decision variables including the duration of Feed and HP, $t_{\mathrm{Feed}}$ and $t_{\mathrm{HP}}$, the flow rate of LP, $\dot{V}_{\mathrm{LP}}$, the evacuation pressure, $P_{\mathrm{BD}-\mathrm{vac}}$, and the Feed composition, are assessed. They were identified as most important decision variables in previous theoretical works $[13,28]$. The operating parameters and variables for the different experiments are summarized in Tables 4 and 5 . The former summarizes all operating parameters that were kept constant for the different cyclic experiments, the latter provides the values of the decision variables that were varied for the different experiments.

We further adapt a more realistic HP in a two-step approach. First, a gas mixture with a composition similar to tail gas $\mathrm{B}$ was used as inlet to $\mathrm{HP}$ rather than pure $\mathrm{CO}_{2}$ (Exp. 9) to assess how this influences the separation performance. Second, an indirect recycle of LP outflow was implemented using the recycle section (Fig. 1, blue lines; Fig. 2, dashed lines) thus avoiding the loss of $\mathrm{CO}_{2}$ in tail gas $\mathrm{B}$.

This section assesses how changing the operating conditions and the process configuration allows to influence purities and recoveries of both products, thus eventually reaching the very high $\mathrm{H}_{2}$ purities required for some industrial applications $(\geq 99.9 \%)$ or for fuel cells $(\geq 99.97 \%)$ and CCS requirements for $\mathrm{CO}_{2}\left(\geq 90 \% \mathrm{CO}_{2}\right.$ recovery, $\geq 96 \% \mathrm{CO}_{2}$ purity).

All experimental results for $\mathrm{CO}_{2}$ and $\mathrm{H}_{2}$ purities and recoveries together with the simulation results are summarized in Table 6 . The most important experimental effects are color-coded in the table. The corresponding tail gas compositions are provided in Fig. 10. A comparison between all experimental and simulated temperature profiles is provided in the supporting information. Reproducibility was confirmed by repeating one of the experiments, Exp. 7, and Table 6 shows the excellent reproducibility.

For the purities, the standard deviation of the measurements evaluated over different cycles is indicated. For the recoveries, the error indicated is based on error propagation calculations. The two repetitions of experiment 7 show the excellent reproducibility of the experiments; note that in all 
subsequent diagrams, we only show the first repetition for this experiment (Color table online)

Most importantly, the experimental results show that:

- increasing the HP duration increases $\mathrm{CO}_{2}$ purity, but slightly decreases $\mathrm{H}_{2}$ purity (Exp. 1 compared to Exp. 3)

- increasing the LP flow rate increases $\mathrm{H}_{2}$ purity, but decreases $\mathrm{CO}_{2}$ recovery (Exp. 1 compared to Exp. 2; Exp. 3 compared to Exp. 4)

- decreasing the evacuation pressure also increases the $\mathrm{H}_{2}$ purity, but at the expense of the $\mathrm{CO}_{2}$ purity (Exp. $6 \mathrm{com}$ pared to Exp. 3 compared to Exp. 7)

- increasing the feed duration decreases $\mathrm{H}_{2}$ purity, but $\mathrm{H}_{2}$ recovery increases; for $\mathrm{CO}_{2}$, the trend is opposite (Exp. 3 compared to Exp. 5)

- small changes in feed stream composition or in HP inlet composition do not affect the separation performance significantly (Exp. 3 compared to Exp. 8 and Exp. 9)

- changing the process configuration to recycle LP outflow (tail gas $\mathrm{B}$ ) as $\mathrm{HP}$ inlet increases the $\mathrm{CO}_{2}$ recovery significantly (Exp. 3 compared to Exp. 10)

These effects are also illustrated in Figs. 11, 12, 13 and 14 and discussed below. The simulated trends are in line with those measured. For a comparison between experiments and simulations in terms of both separation performance indicators (Table 6) and tail gas compositions (Fig. 10), refer to Sect. 4.3; the same effects are seen here. Note that the composition of tail gas B shown in Fig. 10b remains relatively similar for the different experiments and is significantly lower only for the case with a higher LP flowrates (Exp. 2 and 4). The $\mathrm{CO}_{2}$ content is high, making this stream potentially suitable as inlet stream to HP, as assessed indirectly in Exp. 9 and using the recycle section in Exp. 10.

Effect of HP duration The dependency of the separation performance on the HP duration is shown in Fig. 11 with the two experimental points (Exp. 1 and Exp. 3, symbols) and the corresponding simulation results (lines). A can be seen, a longer $\mathrm{HP}$ leads to higher $\mathrm{CO}_{2}$ purities. This happens because more $\mathrm{H}_{2}$ and $\mathrm{CH}_{4}$ are purged out of the column during HP (Fig. 11a). However, with a longer HP, the column top, i.e. the $\mathrm{H}_{2}$ production end, is more contaminated with $\mathrm{CO}_{2}$ and thus the $\mathrm{H}_{2}$ product is more contaminated with $\mathrm{CO}_{2}$ (Fig. 11b). This trend can only be suspected based on the experimental results, but is shown clearly by the simulations.

Effect of LP flow rate The effect of the LP flow rate on the separation performance is illustrated in Fig. 12 for Exp. 3 and Exp. 4 (the same trends can be observed for Exp. 1 and Exp. 2).As shown in the figure, the $\mathrm{H}_{2}$ purity increases significantly with higher LP flow rates. The reason is a better cleaning of the column top from adsorbed $\mathrm{CO}_{2}$, thus decreasing the $\mathrm{CO}_{2}$ contamination of the $\mathrm{H}_{2}$ product (Fig. 12a). It is important to highlight that for $\mathrm{H}_{2}$ with its strict purity requirements, an increase in purity from 99.82 to $99.92 \%$ can be considered a drastic improvement. In contrast to that, the $\mathrm{CO}_{2}$ recovery reduces significantly (Fig. $12 \mathrm{~b}$ ) as more $\mathrm{CO}_{2}$ is wasted from LP outflow and tail gas B contains less $\mathrm{CO}_{2}$ and more $\mathrm{H}_{2}$ (breaking through during LP, Fig. 6a).

Effect of evacuation pressure The effect of decreasing (Exp. 6) and increasing (Exp. 7) the evacuation pressure compared to base case B (Exp. 3) on the separation performance is shown in Fig. 13a. Decreasing the evacuation pressure increases the $\mathrm{H}_{2}$ purity, as it also allows for a better cleaning of the column top. At the same time, the $\mathrm{CO}_{2}$ purity decreases, because the $\mathrm{CO}_{2}$ adsorption front propagates

Table 6 Experimental and simulated separation performance for all experiments; yellow indicates an insignificant change compared to the respective base case, (light) green indicates a (small) improve-

ment, and (light) red indicates a (small) deterioration compared to the respective base case

\begin{tabular}{|c|c|c|c|c|c|c|c|c|}
\hline \multirow{3}{*}{ Exp. \# } & \multicolumn{4}{|c|}{ Purity } & \multicolumn{4}{|c|}{ Recovery } \\
\hline & \multicolumn{2}{|l|}{$\mathrm{H}_{2}$} & \multicolumn{2}{|c|}{$\mathrm{CO}_{2}$} & \multicolumn{2}{|c|}{$\mathrm{H}_{2}$} & \multicolumn{2}{|c|}{$\mathrm{CO}_{2}$} \\
\hline & Exp. & Sim. & Exp. & Sim. & Exp. & Sim. & Exp. & Sim. \\
\hline 1 Base case A & $99.84 \pm 0.01$ & 99.89 & $93.88 \pm 0.09$ & 92.84 & $74.1 \pm 4.0$ & 77.4 & $73.6 \pm 2.1$ & 75.5 \\
\hline $2 \dot{V}_{\mathrm{LP}}+200 \%$ & 99.96 & 99.97 & $92.38 \pm 0.44$ & 90.94 & $73.1 \pm 3.9$ & 75.6 & $68.9 \pm 1.8$ & 73.0 \\
\hline 3 Base case B & $99.82 \pm 0.05$ & 99.85 & $96.08 \pm 0.21$ & 96.85 & $72.7 \pm 4.0$ & 77.8 & $73.2 \pm 1.9$ & 74.2 \\
\hline $4 \dot{V}_{\mathrm{LP}}+200 \%$ & $99.92 \pm 0.01$ & 99.95 & $95.50 \pm 0.14$ & 96.64 & $72.1 \pm 3.9$ & 76.2 & $70.4 \pm 1.6$ & 70.5 \\
\hline $5 t_{\text {Feed }}+23 \%$ & $99.04 \pm 0.03$ & 98.06 & $98.87 \pm 0.04$ & 99.97 & $81.0 \pm 3.8$ & 84.5 & $69.2 \pm 1.7$ & 64.4 \\
\hline $6 P_{\mathrm{BD}-\mathrm{vac}} 21 \%$ & $99.90 \pm 0.04$ & 99.90 & $94.36 \pm 0.34$ & 95.19 & $72.3 \pm 4.0$ & 78.0 & $72.7 \pm 1.9$ & 73.5 \\
\hline $7 P_{\mathrm{BD}-\mathrm{vac}}+21 \%$ & $\begin{array}{l}99.71 \pm 0.02 \\
99.74 \pm 0.01\end{array}$ & 99.78 & $\begin{array}{l}96.55 \pm 0.20 \\
96.60 \pm 0.20\end{array}$ & 98.49 & $\begin{array}{l}75.0 \pm 4.0 \\
73.4 \pm 4.0\end{array}$ & 78.1 & $\begin{array}{l}73.3 \pm 1.8 \\
74.2 \pm 1.9\end{array}$ & 71.6 \\
\hline $8 y_{\mathrm{CH}_{4}}, \mathrm{Feed}^{+50 \%}$ & $99.79 \pm 0.02$ & 99.84 & $94.73 \pm 0.34$ & 96.91 & $74.5 \pm 4.1$ & 77.8 & $74.2 \pm 1.9$ & 75.4 \\
\hline $9 y_{\mathrm{CO}_{2}, \mathrm{HP}}$ & $99.85 \pm 0.02$ & 99.86 & $95.74 \pm 0.16$ & 95.45 & $73.2 \pm 3.9$ & 76.0 & $72.4 \pm 2.5$ & 74.8 \\
\hline $10 \mathrm{HP}$ recycled & $99.81 \pm 0.02$ & 99.83 & $96.49 \pm 0.38$ & 95.09 & $73.8 \pm 3.9$ & 77.3 & $94.3 \pm 1.9$ & 98.1 \\
\hline
\end{tabular}



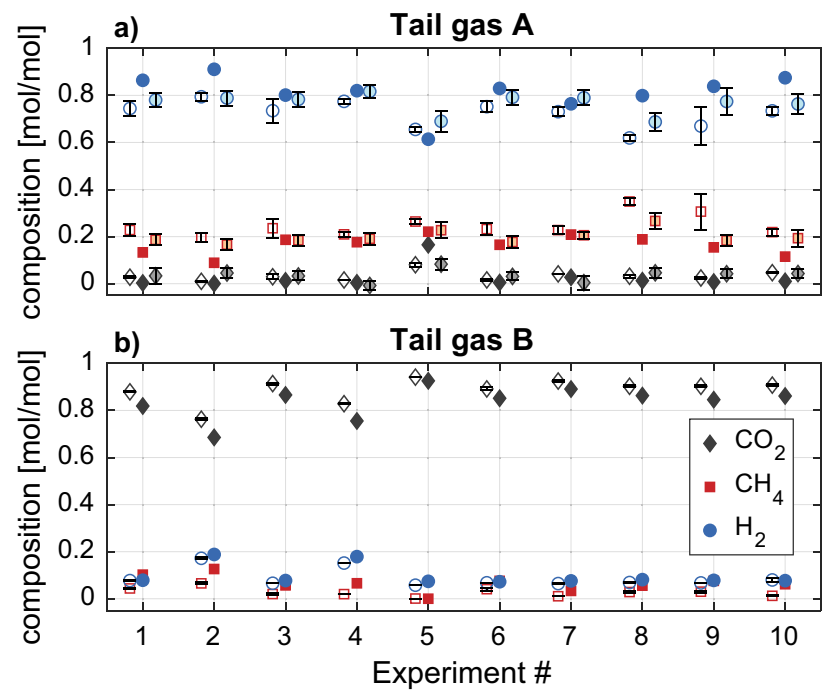

Fig. 10 Composition of tail gas A (a) and B (b). Simulation results are indicated as filled symbols, experimental results as empty symbols shifted slightly to the left. For Tail gas A, the composition calculated from a total mass balance and the measurement of BD, BDvac and Ads are indicated with light filled symbols shifted slightly to the right. Error bars indicate the higher out of standard deviation and error calculated from error propagation to give the best estimate of the experimental uncertainty

slower for a cleaner column, and therefore the column still contains more $\mathrm{H}_{2}$ and $\mathrm{CH}_{4}$ at the end of HP.

Effect of feed duration Figure 13b shows the dependency of the process performance on the feed duration. When increasing the feed duration (Exp. 5), the $\mathrm{H}_{2}$ purity decreases because $\mathrm{CH}_{4}$ breaks through. At the same time, the $\mathrm{H}_{2}$ recovery increases significantly. The $\mathrm{CO}_{2}$ purity also increases, because the $\mathrm{CO}_{2}$ adsorption front propagates further through the column during Ads and HP, even breaking through at the end of HP (see corresponding temperature and concentration profiles provided in the supporting information), which in turn reduces the $\mathrm{CO}_{2}$ recovery.

Effect of feed composition Figure 14a shows the dependency of the process performance on the feed composition, i.e. an increasing impurity content (Exp. 8). The performance changes only little, because also for the higher $\mathrm{CH}_{4}$ content, the impurity does not break through and a similar $\mathrm{H}_{2}$ purity as for base case B is reached. Note that the simulations predict $\mathrm{CH}_{4}$ breakthrough and a fast decrease in $\mathrm{H}_{2}$ purity above a threshold impurity content, that is higher than that tested experimentally. To still reach high $\mathrm{H}_{2}$ purities in those cases, the feed duration should be decreased, as explained in the previous point.

Effect of HP inlet composition One of the main simplifications of all experiments discussed above is the use of pure $\mathrm{CO}_{2}$ for HP. As first step toward a more realistic HP, before implementing an indirect recycle, the composition of the HP inlet was changed in Exp. 9: a gas-bottle with a lower
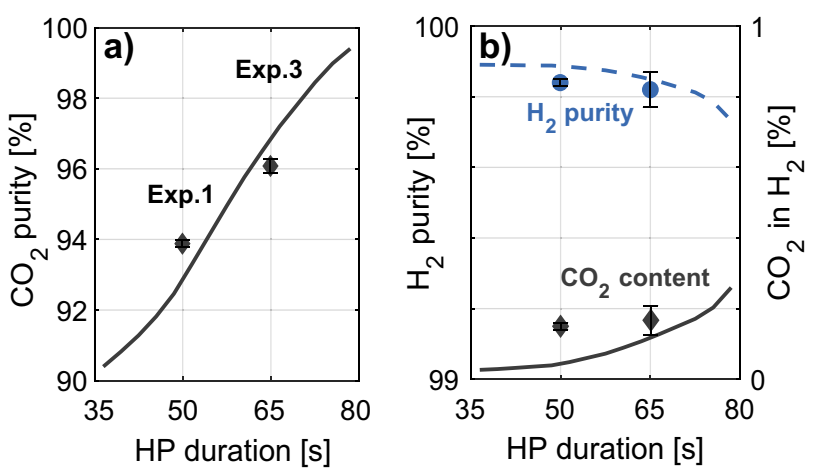

Fig. 11 Influence of HP duration on $\mathrm{CO}_{2}$ purity (a) and $\mathrm{H}_{2}$ product composition (b). Experimental (symbols) and simulation (lines) results are shown. Error bars indicate the standard deviation over several cycles at CSS for the purity and the experimental uncertainty calculated through error propagation for the recovery
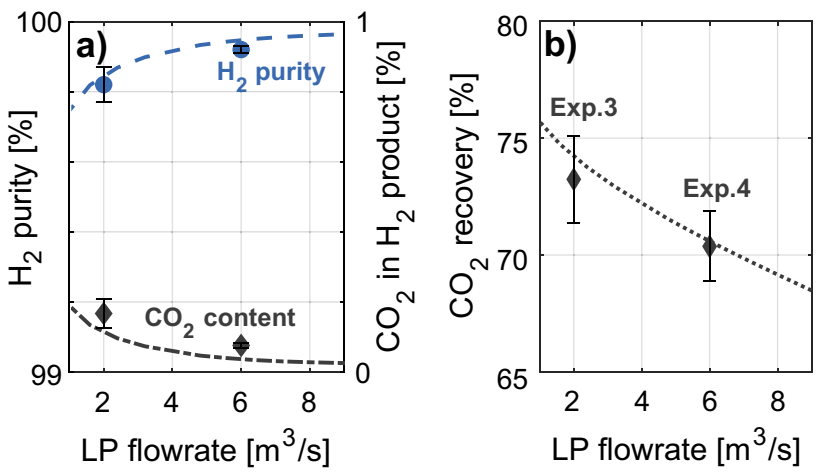

Fig. 12 Influence of LP flow rate on $\mathrm{H}_{2}$ purity (a) and $\mathrm{CO}_{2}$ recovery (b). Experimental (symbols) and simulation (lines) results are shown. Error bars indicate the standard deviation over several cycles at CSS (purity) and the experimental uncertainty calculated through error propagation (recovery)
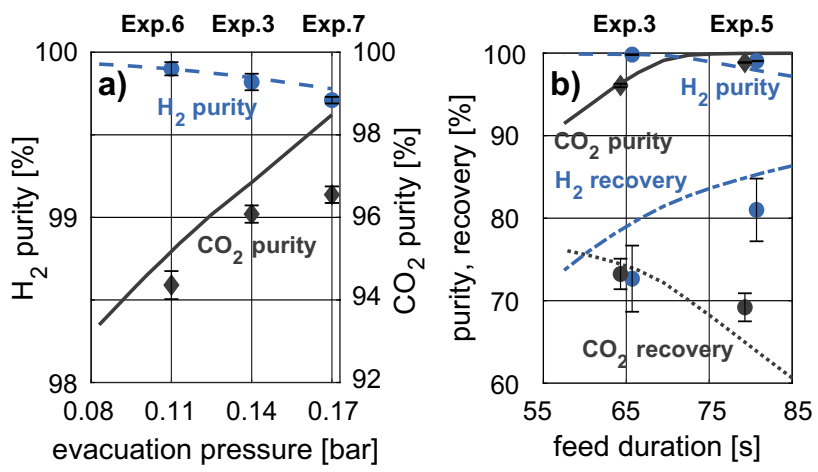

Fig. 13 Influence of evacuation pressure (a) and feed duration (b) on separation performance. Experimental results are shown with symbols and simulation results with lines. Error bars indicate the standard deviation over several cycles at CSS (purity) and the error propagation calculations (recovery) 

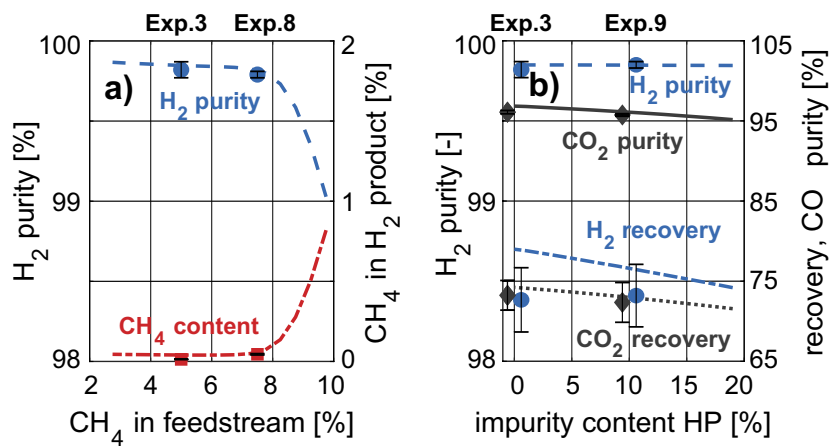

Fig. 14 a Experimental (points) and simulation (lines) results for $\mathrm{H}_{2}$ product composition for change in feed stream composition. The $\mathrm{CO}_{2}$ content in the feed is kept constant, an increase / decrease in $\mathrm{CH}_{4}$ content thus translates to a decrease/increase in $\mathrm{H}_{2}$ content in the feed. $\mathbf{b}$ Change in separation performance for changing impurity content in $\mathrm{HP}$ inlet. The ratio of $\mathrm{H}_{2}: \mathrm{CH}_{4}$ is kept constant at $4: 1$

$\mathrm{CO}_{2}$ content and a composition informed by the typical composition of tail gas B was used (Fig. 10b; Table 5). The results for this change in HP inlet composition are shown in Fig. 14b. It can be seen that changing the HP inlet affects the separation performance only little and no clear trend can be confirmed experimentally. Simulations suggest, however, a slow decrease in $\mathrm{CO}_{2}$ purity with increasing impurity content in the HP inlet. The reasons is a lower purge efficiency because the column gas phase is replaced not with pure $\mathrm{CO}_{2}$, but with an impure gas mix, and because the molar amount of $\mathrm{CO}_{2}$ entering the column decreases with increasing impurity content. It is important to highlight that tail gas B separated in Exp. 9 has a composition similar to the composition of the gas bottle used as HP inlet with slightly more $\mathrm{CH}_{4}(3 \%$ instead of $2 \%$ ) and less $\mathrm{H}_{2}$ (6\% instead of $8 \%$ ). These results show that it is promising to use tail gas B for the HP, which we did in a final experiment.

Effect of recycle section For Exp. 10, an indirect recycle of tail gas B to the HP inlet was implemented (see Fig. 4, dashed lines). Except for the HP inlet, the experiment is equivalent to Exp. 3. All of tail gas B produced from column 1 is recycled to a storage tank and used in the next half cycle for the HP of column 2, and vice versa. At CSS, 0.115 $\pm 0.002 \mathrm{~mol}$ are recycled to the HP each half-cycle, corresponding to an inflow of approximately $4.33 \pm 0.1 \mathrm{E}-05$ $\mathrm{m}^{3} / \mathrm{s}$ at HP conditions. This inflow is almost $10 \%$ higher than for Exp. 3 and Exp. 9. Related to this, also the measured $\mathrm{CO}_{2}$ purity is higher than for Exp. 3 and Exp. 9 (see Table 6). The composition of tail gas B (measured at the end of the experiment, when emptying the storage tank) is close to that used in cycle 9 with slightly more $\mathrm{CO}_{2}$ and slightly less $\mathrm{CH}_{4}\left(\mathrm{CO}_{2}: \mathrm{H}_{2}: \mathrm{CH}_{4}=90.8: 8.0: 1.2 \mathrm{~mol} \%\right.$ compared to 90:8:2 mol\% for Exp. 9, see Fig. 10b).

$\mathrm{H}_{2}$ purity and recovery do not change notably. The $\mathrm{CO}_{2}$ recovery, however, increases dramatically now that the LP outflow is recycled as inflow for HP rather than wasted resulting in a measured recovery $>94 \%$. With this, the cycle configuration with recycle reaches the target of $96 \%$ purity and $90 \%$ recovery often set for carbon capture and storage applications, thereby demonstrating the feasibility of VPSA technology for carbon capture with integrated $\mathrm{H}_{2}$ purification.

Process optimization It is important to highlight that the parametric analysis carried out in this work does not result in an optimized performance of the VPSA process. Because the different process steps are interlinked, such an optimization would require to change the different decision variables simultaneously, i.e. the optimum of one variable cannot be found independently of the others. For example: given the base case $\mathrm{B}$ values of the decision variables, lowering the evacuation pressure results in a decrease in $\mathrm{CO}_{2}$ purity as discussed above (Exp. 6). Hence, based on this analysis only, decreasing the evacuation pressure seems unfavorable for increasing the $\mathrm{CO}_{2}$ purity. However, the decrease in $\mathrm{CO}_{2}$ purity could easily be counteracted, for example by increasing the HP duration. When optimizing the process by simultaneously changing several decision variables, we have shown that a lower evacuation pressure is indeed favorable for both $\mathrm{CO}_{2}$ and $\mathrm{H}_{2}$ separation performance [14]. This highlights the importance of a reliable model, that can be used to mathematically optimize the process and find an optimal configuration, as we have done in previous works $[13,14]$. Nevertheless, the experimental analysis carried out in this work allows appreciating the effect of key operating variables on separation performance. Such insight can be exploited to fine-tune specific key performance indicators by adjusting the operating conditions in the direction indicated by the experimental study.

\section{Conclusions}

In this paper, we presented an experimental and modeling study of VPSA cycles for $\mathrm{CO}_{2}-\mathrm{H}_{2}$ co-purification from a ternary inlet stream representing shifted SMR syngas using commercial zeolite 13X. The VPSA cycles achieved the co-purification of both products. A maximum $\mathrm{H}_{2}$ purity of $99.96 \%$ (at $92.38 \% \mathrm{CO}_{2}$ purity) and a maximum $\mathrm{CO}_{2}$ purity of $98.87 \%$ (at $99.0 \% \mathrm{H}_{2}$ purity) were reached. The $\mathrm{CO}_{2}$ recovery was limited $(<75 \%)$ for cycle configurations without recycle. It could be increased drastically when recycling one of the two produced tail gas streams resulting in a $\mathrm{CO}_{2}$ recovery $>94 \%$ (at $96.5 \% \mathrm{CO}_{2}$ purity). The $\mathrm{H}_{2}$ recovery was low for most cases $(\approx 75 \%)$, due to the limited number of pressure equalization steps-one PE only can be carried out in the two-column lab setup.

The effect of important decision variables on the performance was assessed. Those are the LP flow rate, the HP 
duration, the feed duration, the evacuation pressure and the $\mathrm{HP}$ inlet composition. For increasing the $\mathrm{H}_{2}$ purity, either the LP flow rate should be increased, or the evacuation pressure decreased. Both decrease the $\mathrm{CO}_{2}$ contamination of the column top, i.e. the $\mathrm{H}_{2}$ production side, and thus the $\mathrm{CO}_{2}$ content of the $\mathrm{H}_{2}$ product. The former, however, decreases the $\mathrm{CO}_{2}$ recovery, and the latter requires more energy. The feed duration is another key factor determining $\mathrm{H}_{2}$ purity: after a critical duration, $\mathrm{CH}_{4}$ impurity starts breaking through, thus quickly decreasing the $\mathrm{H}_{2}$ product purity. Longer feed durations, however, are favorable for reaching higher $\mathrm{H}_{2}$ recoveries. Therefore, the feed should be stopped just before $\mathrm{CH}_{4}$ breakthrough. The duration of the HP is the most important decision variable for controlling the $\mathrm{CO}_{2}$ purity, with little influence on the $\mathrm{H}_{2}$ separation performance. The HP should be stopped just before $\mathrm{CO}_{2}$ breakthrough occurs. This ensures a high $\mathrm{CO}_{2}$ purity, but reduces its loss. A high $\mathrm{CO}_{2}$ purity could be reached also with an impure HP inlet stream consisting of only $90 \% \mathrm{CO}_{2}$. The inlet can be provided externally using a gas bottle, or internally using a recycled stream from the $\mathrm{LP}$ outlet, which is preferable as it increases $\mathrm{CO}_{2}$ recovery.

In addition to those decision variables, we assessed the sensitivity of the VPSA cycle towards changes in impurity content, as can occur during the operation of an SMR. We therefore increased the $\mathrm{CH}_{4}$ concentration from 5 to $7.5 \%$. The VPSA cycle can withstand this change in inlet composition with only little variation in the process performance. Higher impurity concentrations, however, quickly lead to a decrease in $\mathrm{H}_{2}$ purity as $\mathrm{CH}_{4}$ breaks through.

A comparison between experimental and simulation results was carried out comparing different models for multicomponent adsorption. A comparison of the temperature profiles within the column showed that the propagation of the $\mathrm{CO}_{2}$ front is simulated correctly neither with IAST nor with extended isotherms. Extended isotherms nevertheless reproduce the composition profiles well. In contrast to that, IAST gives a better representation of the propagation of the $\mathrm{CO}_{2}$ adsorption front, but underestimates $\mathrm{CH}_{4}$ co-adsorption to such an extent, that it is predicted to break though together with $\mathrm{H}_{2}$ without prior production of high purity $\mathrm{H}_{2}$ product. RAST results in a far better prediction of both temperature and composition profiles accurately predicting the timing of the temperature fronts, and $\mathrm{H}_{2}$ as well as $\mathrm{CO}_{2}$ product compositions.

The downstream piping of the experimental setup combined with shared pipes for different outflows at both high and low pressure made an evaluation of the separation performance and a comparison with the simulated separation performance, as well as a comparison of the measured with the simulated composition profiles, less accurate than the comparison of the temperature profiles. To enable a meaningful comparison also in these cases, we have considered the influence of the piping in addition to idle times and measurement errors to reconcile experimental and simulated data. With this, a good agreement of measured and simulated composition profiles and performance indicators could be confirmed. Moreover, the trends for all performance indicators are reproduced at least qualitatively; for both purities and the $\mathrm{CO}_{2}$ recovery, even a good quantitative agreement is achieved.

Summarizing, we validated our adsorption model for the simulation of VPSA for $\mathrm{H}_{2}-\mathrm{CO}_{2}$ co-purification. In addition, we successfully demonstrated the technology at lab-pilot scale and identified the key decision variables for controlling the process performance. This successful small-scale testing of the new technology, in combination with an accurate model that can be used to optimize the technology, paves the way towards a larger scale testing and application of VPSA for enabling efficient low-carbon fossil-based $\mathrm{H}_{2}$ production combined with CCS.

Supplementary Information The online version contains supplementary material available at https://doi.org/10.1007/s10450-021-00308-w.

Acknowledgements ACT ELEGANCY, Project No 271498, has received funding from DETEC $(\mathrm{CH})$, BMWi (DE), RVO (NL), Gassnova (NO), BEIS (UK), Gassco, Equinor and Total, and is cofunded by the European Commission under the Horizon 2020 programme, ACT Grant Agreement No 691712. This project is supported by the pilot and demonstration programme of the Swiss Federal Office of Energy (SFOE).

Funding Open Access funding provided by ETH Zurich..

\section{Declarations}

Conflict of interest The authors declare that they have no conflict of interest.

Open Access This article is licensed under a Creative Commons Attribution 4.0 International License, which permits use, sharing, adaptation, distribution and reproduction in any medium or format, as long as you give appropriate credit to the original author(s) and the source, provide a link to the Creative Commons licence, and indicate if changes were made. The images or other third party material in this article are included in the article's Creative Commons licence, unless indicated otherwise in a credit line to the material. If material is not included in the article's Creative Commons licence and your intended use is not permitted by statutory regulation or exceeds the permitted use, you will need to obtain permission directly from the copyright holder. To view a copy of this licence, visit http://creativecommons.org/licenses/by/4.0/.

\section{References}

1. European Commission: A hydrogen strategy for a climate-neutral Europe. https://ec.europa.eu/energy/sites/ener/files/hydrogen_strat egy.pdf (2020)

2. IEA: The future of hydrogen. https://www.iea.org/reports/thefuture-of-hydrogen, Paris (2019) 
3. Nuttall, W.J., Bakenne, A.T.: Towards a Hydrogen Economy, pp. 43-52. Springer International Publishing, Cham (2020)

4. Antonini, C., Treyer, K., Streb, A., van der Spek, M., Bauer, C., Mazzotti, M.: Hydrogen production from natural gas and biomethane with carbon capture and storage-a techno-environmental analysis. Sustain. Energy Fuels 4, 2967-2986 (2020). https://doi. org/10.1039/D0SE00222D

5. IEAGHG: Techno-economic evaluation of SMR based standalone (merchant) hydrogen plant with CCS. https://ieaghg.org/ exco_docs/2017-02.pdf, 2017-TR3 (2017)

6. Voldsund, M., Jordal, K., Anantharaman, R.: Hydrogen production with $\mathrm{CO}_{2}$ capture. Int. J. Hydrogen Energy 41(9), 4969 4992 (2016). https://doi.org/10.1016/j.ijhydene.2016.01.009

7. Alberta Department of Energy: Quest carbon capture and storage project: annual report. 2011-2018. https://open.alberta.ca/ dataset?tags $=\mathrm{CCS}+$ knowledge + sharing + program\&tags $=$ Quest +Carbon+Capture+and+Storage+project (2012-2019)

8. Air Products and Chemicals, Inc, Busse, A., Power, G., MacMurray, J.: Demonstration of carbon capture and sequestration of steam methane reforming process gas used for large-scale hydrogen production. (2018)https://doi.org/10.2172/1437618

9. Pichot, D., Granados, L., Morel, T., Schuller, A., Dubettier, R., Lockwood, F.: Start-up of Port-Jérôme CRYOCAP ${ }^{\mathrm{TM}}$ plant: optimized cryogenic $\mathrm{CO}_{2}$ capture from $\mathrm{H}_{2}$ plants. Energy Procedia 114, 2682-2689 (2017). https://doi.org/10.1016/j.egypr o.2017.03.1532

10. METI, NEDO, JCCS: Report of Tomakomai CCS demonstration project at 300 thousand tonnes cumulative injection (“summary report"). https://www.meti.go.jp/english/press/2020/ pdf/0515_004a.pdf (2020)

11. Sircar, S., Kratz, W.C.: Simultaneous production of hydrogen and carbon dioxide from steam reformer off-gas by pressure swing adsorption. Sep. Sci. Technol. 23, 2397-2415 (1988). https://doi.org/10.1080/01496398808058461

12. Sircar, S., Golden, T.C.: Pressure Swing Adsorption Technology for Hydrogen Production. John Wiley \& Sons Inc, Hoboken (2010)

13. Streb, A., Mazzotti, M.: Novel adsorption process for co-production of hydrogen and $\mathrm{CO}_{2}$ from a multicomponent stream - part 2: application to SMR and ATR gases. Ind. Eng. Chem. Res. 59(21), 10093-10109 (2020). https://doi.org/10.1021/acs. iecr.9b06953

14. Streb, A., Hefti, M., Gazzani, M., Mazzotti, M.: Novel adsorption process for co-production of hydrogen and $\mathrm{CO}_{2}$ from a multicomponent stream. Ind. Eng. Chem. Res. 58(37), 1748917506 (2019a). https://doi.org/10.1021/acs.iecr.9b02817

15. Streb, A., Mazzotti, M.: Adsorption for efficient low carbon hydrogen production - part 1: adsorption equilibrium and breakthrough studies for $\mathrm{H}_{2} / \mathrm{CO}_{2} / \mathrm{CH}_{4}$ on zeolite $13 \mathrm{X}$. Adsorption. (2021). https://doi.org/10.1007/s10450-021-00306-y

16. NETL: Quality guidelines for energy system studies: $\mathrm{CO}_{2} \mathrm{impu}-$ rity design parameters. https://doi.org/10.2172/1566771 (2019)

17. de Visser, E., Hendriks, C., Barrio, M., Mølnvik, M.J., de Koeijer, G., Liljemark, S., Gallo, Y.L.: Dynamis $\mathrm{CO}_{2}$ quality recommendations. Int. J. Greenhouse Gas Control 2(4), 478484 (2008). https://doi.org/10.1016/j.ijggc.2008.04.006

18. Marx, D., Joss, L., Hefti, M., Mazzotti, M.: Temperature swing adsorption for postcombustion $\mathrm{CO}_{2}$ capture: single- and multicolumn experiments and simulations. Ind. Eng. Chem. Res. 55(5), 1401-1412 (2016). https://doi.org/10.1021/acs. iecr.5b03727

19. Schell, J., Casas, N., Marx, D., Mazzotti, M.: Precombustion $\mathrm{CO}_{2}$ capture by pressure swing adsorption (PSA): comparison of laboratory PSA experiments and simulations. Ind. Eng. Chem. Res. 52(24), 8311-8322 (2013). https://doi.org/10.1021/ie3026532

20. Specchia, V., Baldi, G., Sicardi, S.: Heat transfer in packed bed reactors with one phase flow. Chem. Eng. Commun. 4, 361-380 (1980). https://doi.org/10.1080/00986448008935916

21. Casas, N., Schell, J., Joss, L., Mazzotti, M.: A parametric study of a PSA process for pre-combustion $\mathrm{CO}_{2}$ capture. Sep. Purif. Technol. 104, 183-192 (2013). https://doi.org/10.1016/j.seppu r.2012.11.018

22. Hefti, M., Marx, D., Joss, L., Mazzotti, M.: Adsorption equilibrium of binary mixtures of carbon dioxide and nitrogen on zeolites ZSM-5 and 13X. Microporous Mesoporous Mater. 215, 215-228 (2015). https://doi.org/10.1016/j.micromeso.2015.05.044

23. Wilson, G.M.: Vapor-liquid equilibrium. XI. a new expression for the excess free energy of mixing. J. Am. Chem. Soc. 86, 127-130 (1964). https://doi.org/10.1021/ja01056a002

24. Rajendran, A., Kariwala, V., Farooq, S.: Correction procedures for extra-column effects in dynamic column breakthrough experiments. Chem. Eng. Sci. 63(10), 2696-2706 (2008). https://doi. org/10.1016/j.ces.2008.02.023

25. Krishnamurthy, S., Haghpanah, R., Rajendran, A., Farooq, S.: Simulation and optimization of a dual-adsorbent, two-bed vacuum swing adsorption process for $\mathrm{CO}_{2}$ capture from wet flue gas. Ind. Eng. Chem. Res. 53(37), 14462-14473 (2014). https://doi. org/10.1021/ie5024723

26. Li, G., Xiao, P., Zhang, J., Webley, P.A., Xu, D.: The role of water on postcombustion $\mathrm{CO}_{2}$ capture by vacuum swing adsorption: bed layering and purge to feed ratio. AIChE J. 60(2), 673-689 (2014). https://doi.org/10.1002/aic.14281

27. Subraveti, S.G., Li, Z., Prasad, V., Rajendran, A.: Machine learning-based multiobjective optimization of pressure swing adsorption. Ind. Eng. Chem. Res. 58(44), 20412-20422 (2019). https:// doi.org/10.1021/acs.iecr.9b04173

28. Streb, A., van der Spek, M., Joersboe, J., Asgari, M., Queen, W., Mazzotti, M.: Report on characterization of equilibria and transport phenomena in promising new adsorbents for $\mathrm{CO}_{2} / \mathrm{H}_{2}$ separation. https://www.sintef.no/projectweb/elegancy/publications/, deliverable 1.1.2. of the ELEGANCY project (2019b)

Publisher's Note Springer Nature remains neutral with regard to jurisdictional claims in published maps and institutional affiliations.

\section{Authors and Affiliations}

\section{Anne Streb ${ }^{1}\left[\right.$ ] Marco Mazzotti ${ }^{1}[$}

Marco Mazzotti

marco.mazzotti@ipe.mavt.ethz.ch
1 ETH Zurich, Institute of Energy and Process Engineering, 8092 Zurich, Switzerland 